\title{
DETERMINAÇÃO DA CURVA DE RETENÇÃO DA ÁGUA NO SOLO ATRAVÉS DO FATIAMENTO DE AMOSTRAS CENTRIFUGADAS
}

\author{
SOLANGE DIAS DE MEDEIROS \\ Engenheira Civil
}

Orientador: Prof. Dr. RUBENS SCARDUA

Dissertação apresentada à Escola Superior de Agricultura "Luiz de Queiroz", da Universidade de São Paulo, para obtenção do título de Mestre em Irrigação e Drenagem.

\footnotetext{
PIR A C I C A B A

Estado de São Paulo - Brasil

Abril - 1987
} 
- ii.

Aos meus pais: JOSE DIAS e MARIA EVANI

(in memorian) e

aos meus irmãos,

DEDICO.

Ao meu esposo ALDO

e ao meu filho MARCEI,

OFEREÇO. 


\section{AGRADECIMENTOS}

Ạ Deus, pela fé e perseverança concedida em todos os momentos.

Ao Prof. Dr. RUBEnS SCARDUA pela ségura orientação, dedicação e colaboração oferecidas na execução deste traba tho.

Ao Prof. Dr. VALDEMAR ANTONIO DEMÉTRIO pela sugestão do Tema e incentivo nos dois primeiros anos do curso.

Ao Prof. Dr. DÉCIO BARBIN pelas sugestões na elaboração das análises estatisticas.

AO Prof. Dr. TARLEI ARRIEL BOTREL pelas sugestões e incen tivo.

Ao Dr. ELIAS DE FREITAS JUUNIOR pelo incentivo e sugestões na elaboração deste trabalho.

Aos funcionários do Departamento de Engenharia Rural pela ajudz e amizade, especialmente HÉLIO TOJEDO GOMES pela w.bobação nas análises de laboratório. 
A Secretaria da Agricultura - RN e a Companhia Integrada de Desenvolvimento Agropecuário - RN, pela oportunidade concedida à participação do curso.

A Escola Superior de Agricultura "Luiz de Queiroz" pelos ensinamentos ministrados.

Ao Conselho Nacional de Pesquisa, pela bolsa concedida.

Aos colegas do curso pelo convívio amigo.

A todos que contribuíram direta ou indiretamente para a e laboração deste trabalho. 


\section{INDICE}

Pàgina

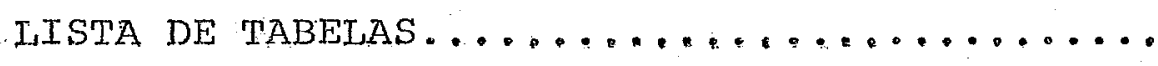

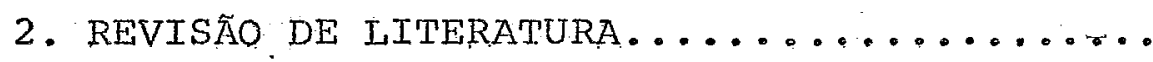

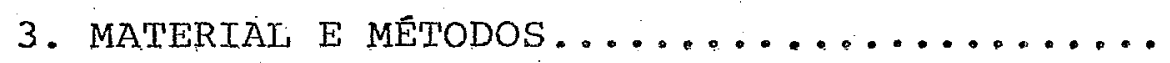

3.1. Loda $1 \ldots \ldots \ldots \ldots \ldots \ldots \ldots \ldots \ldots \ldots \ldots \ldots \ldots \ldots \ldots$

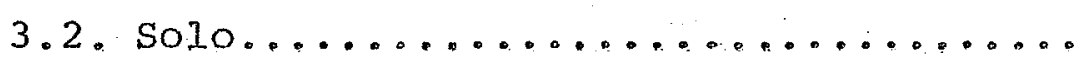

3.3. Preparação das amostras do solo.....

3.4. Curvas caracteristicas de água no so10

3.4.1. Determiração cia curva ce retenção, conforme metociologia estabelecica por

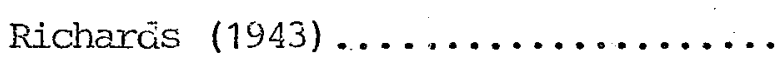

3.4.2. Determinação đa curva de retenção usando o fatiamento de amostras centrifugadas.

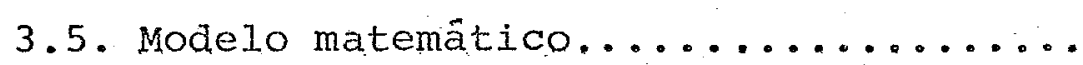

4. RESULTADOS E DISCUSSÃO............... 26

4.1. Densidade global (DG) ............

4.2. Cur ras de estabilização de umidade do soio. 
pàgina

4.3. Curvas de recenção da...àgua no

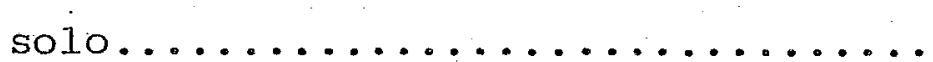

4.3.1. Curvas de retenção da āgua no solo determinadas nas câma-. ras de pressão de Richards....

4.3.2. Curva àe retenção da àgua no solo determinada na centri-

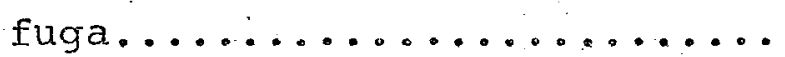

4.3.3. Relaçôes entre as curvas de retenção da água no solo obtidas pelos métodos estudados.....

4.4. Correlação entre os métodos estudados

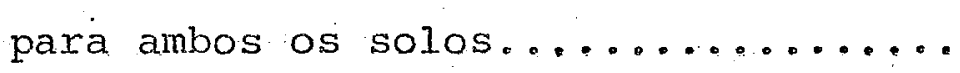
4.4 .1 . Solo sertãozinho........... 46 4.4.2. Solo, Luiz de Queiroz......... 50

5. CONCLUSOES.......................... 53

6. REFERENCIAS BIBLIOGRÁFICAS............. 55

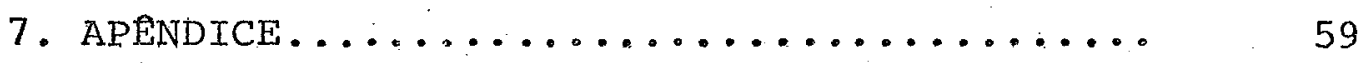


-vii.

LISTA DE TABELAS

TABELA

pāgina

1 Granulometria e classe textural....

2 Densidade global dos solos estuda$d o s \ldots \ldots \ldots \ldots \ldots \ldots \ldots$

27

9. Valores médios do teor de ạgua do solo em função do tempo e da veloci dade angular de cntrifugação. Solo

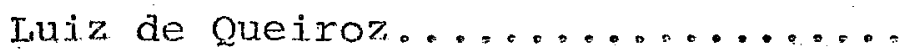

Vajores médios do teor de água do solo em função do tempo e da veloci dade angular de centrifugacão. Solo Sertãozinho...................

Valores médios do teor de água do solo em função da tensão determinada na câmara de pressão. Solo Luiz de Queiroz, $20-40 \mathrm{~cm} . . . . . . .$. 
4 Valores médios do teor de âgua do solo em função da tensão determinada ṇa câmara de pressão. Solo Sertãozinho -

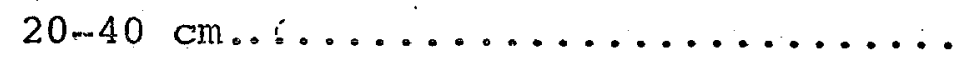

5 Valores médios do teor de água do so10 em função do potencial médio calcu lados por camada, para diferentes valores de velocidade angulax em uma cen trifuga com $r_{0}=5,3 \mathrm{~cm}$. Para o solo

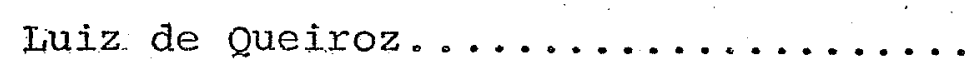

Valores médios do teor de āgua do so1o em função do potencial matricial médio calculados por camada, para diferentes valores de velocidade angulax em uma centrifuga com $r_{0}=5,3 \mathrm{~cm}$. Para o solo sertãozinho............

7 Anậlise da varianncia para os métodos estudaco: Para o solo sertãozinho... 
Análise da variância para os métodos estudados. Para o solo Luiz de Queiroz.

11 Valores da tensão da água do solo, umidades $\%$ em peso e o em volume, determinada na câmara de pressão. Solo Luiz de Queiroz, $20-40 \mathrm{~cm} . . . . . .$.

Valores da tensão da âgua do solo, um midades $:$ em peso e em volume, determinada na câmara de pressão. Solo Sertãozinho, $20-40 \mathrm{~cm} \ldots \ldots \ldots \ldots \ldots$

13 Valores da tensão da água do solo, umidades $\%$ em peso e \% em volume, determinada na centrifuga. Solo Luiz de Queiroz, $20-40 \mathrm{~cm} . . . \ldots \ldots . . .$.

14 Valores da tensão da: água do solo, umidades $: \dot{0}$ em peso e $\%$ em volume, determinada na centrífuga. Solo Sertãozinho, $20-40 \mathrm{~cm} \ldots \ldots \ldots \ldots \ldots \ldots \ldots \ldots$ 

no tambor da centrífuga e as respectivas peças de madeira...........

Extrator hidrâulico, utilizado no fa tiamento das amostras.............

4 : Representação esquemática de uma amostra na centrífuga............

5 Curvas de estabilização de umidade em amostras do T.Sim submetidas à cen-

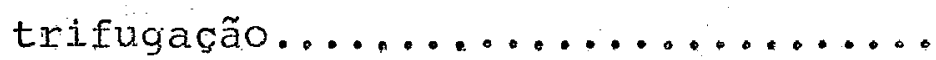

Curvas de estabilização de umidade em amostras do TRE submetidas à cen-

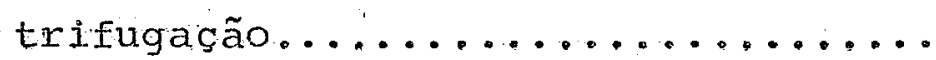

7. Curva cie retenção d. Agua no solo. Solo sertãozinho $(20-40 \mathrm{~cm}) \ldots \ldots$ 
Curva de retenção àa água no solo. Solo Luiz de Queiroz $(20-40 \mathrm{~cm}) \ldots . .$.

Curva cie retenção cia ägua no solo cieter minada na centrífuga. Soló Luiz de

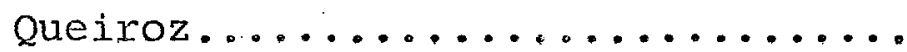

10 Curva c̈e retenção da água no solo determinada na centrífuga. Solo Sertãozi

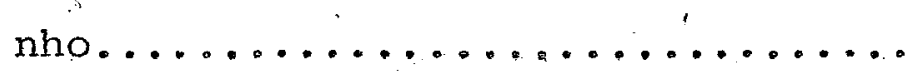

11 : Curvas ảe retenção da água no solo pelos métodos da centrífuga e das câmaras de pressão - Solo tuiz de cueiroz $\left(20-40 \mathrm{~cm}^{\circ}\right)$

12 Curvas ce retenção da ägua no solo, pelos métodos da centrífuga e das cầmaras de pressão - Solo Sertãozinho $(20-40 \mathrm{~cm})$

Relação das umidades entre os mëtodos estudados para o solo sertãozinho $(L V m) \ldots \ldots \ldots \ldots \ldots$ 
14. Intervalo de confiança para a regressão Iinear. Solo sertãozinho.........

15 Relação das umidades entre os métodos estudados para o solo Luiz de Queiroz TRE.

Intervalo de confiança para a regressão linear. Solo luiz de Queiroz..... 


\title{
DETERPINACÃO DA CURYA DE RETERCGO DE AGUA ATRAVES DE AMOSTRAS SURMETIDAS A CEPTTRIFUGACÃO DO FATIAMEFTO
}

\author{
Autor: SOIANGE DIAS DE MEDEIROS \\ Orientador: Prof. Dr. RUBENS SCARDUA
}

\section{RESUHO}

No presente trabalho procurou-se avaliar a funcionalidade do método àe fatiamento para à determinação da curva caracteristica da āgua do solo, tendo como comparação o método tradicional pelo uso de placas em câmaras de pressão de RICFARDS. Foram usados dois solos do Municipio de Piracicaba, Terra Roxa estruturada (TRE) e Latossolo Vermelho Amarelo (INm) com caracteristicas físicas e morfológicas contrastantes, com amostras à profundidade de $40 \mathrm{~cm}$.

Amostras äos solos foram submetidas a centrifu gação para determinar a umidade em função do tempo e verificar - tempo de estabilização de umidade para ambos os solos em cin co velocidades angulares e seis intervalos de tempo. Foi verificado que no solo sertãozinho $(\mathrm{IVm})$ o tempo de equilibrio ocorreu aos 180 minutos e no solo Luiz dẹ Queiroz aos $240 \mathrm{minu-}$ tos. Após o :quilíbrio, amostras de $6 \mathrm{~cm}$ de espessura foram fatiadas a cada $2 \mathrm{~cm}$ de erpessura. roi deterninado o teor de ăgua de cada fatia e correlacionada com o potencial corresponaente 
para estabelecer a curva de retenção da água no solo. As curvas da água no solo determinadas em cada método, foram analisa das pelo estudo de regressão simples e feitas as comparações pela análise de correlação. Os resultados mostraram uma boa correlação significativa entre os métodos para ambos os solos, o que vem demonstrar a validade do fatiamento. 


\title{
DETERPIIUACION OF THE SOLL MOISTURE RETENTIOAN CURVE THROUGH THE USE OF A SLICING METHOD APPLIED. TO CEMTIFUGED SOIL CORES
}

\author{
AUTHOR: Solange Dias de Medeiros \\ ADVISER: Prof. Dr. Rubens Scardua
}

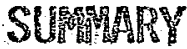

This presente work was designed to asses the

- slicing method for determination of the soil moisture retention curve, as compared to the traditional method using the Richards' pressure plate apparatus.

Two types of soils from Piracicaba county were used. A Latossolo Vermelho-Amarelo and a Terra Roxa Estruturada with contrasting physical and morphological characteristics, sampled to $40 \mathrm{~cm}$ depth.

Soil samples were submitted to centrifugation in order to determine moisture as a function of time to asses the moisture stabilization for both soils, at five angular velocities and six time intervals. It was determined that in the sandy-loam soil, the equilibrium time occured at 180 minutes and in the clay-loam soil at 240 minutes.

After equilibration, the $6 \mathrm{~cm}$ long cores weis split into three siices $2 \mathrm{~cm}$ long. The water content of eacin slice was determined and correlated to the corresponding 
potencial to stablish the soil moisture retention curve.

The soil moisture retention curves determined

for this method and by the pressure plate were analysed by the single regression method and compared by correlation analysis. The results showed good correlation between the methods for both soils, which indicates the validity of the slicing method. 


\section{INT'RODUÇAO}

o homem tem procurado constantemente aumentar a produção de alimentos por meio da incorporação de novas áreas ao sistema de produção ou aumentar a produtividade das āreas jā incorporadas. A ùltima alternativa, que ciepende do desenvolvimento de novas técnicas e aperfeiçoamento das existentes, tem recebido mais atenção atualmente. Das técnicas já em uso, a irrigação é uma qué vem sendo pesquisada, frequentemente, visando encontrar maneiras mais adequadas de utilização da água, que ao atingir a superfí cie do solo, se infiltra e se redistribui no perfil do sọ 1o, proporcionando à umidadé necessária ao desenvolvimento das culturas.

Consideráve? atenção tem sido dada ao fator água no estudo do sistema solo-água-planta, pois a umidade do solo é um dos fatores que mais contribuem para a produtividade das culturas. A caracterização da água no solo pode ser feita com o estado de energia com que é retida pelo., solo. Este estado energētico, que caracteriza água no solo, é constituído por diferentes formas e quantidades de energia. A fisica reconhece duas formas princi pais de energia: a cinética e a potencial, contuäo em ter mos da dinâmica dá água no solo, a priroira forme de energia édes 
prezível uma vez que a velocidade d'água no solo é muito pequena na maioria dos casos. A energia potencial que é dada em função da posição e/ou condição interna d'água no ponto considerado, é de grande importância na caracterizạ ção do seu estado energético.

A fim de se dar suporte técnico aos projetos de irrigação é necessário que se conheça adequadamente as características fisicas do solo que influem no manejo da irrigação. Dentre estas características, aquelas que determinar. "curva de retenção da água no solo, possuem uma importância primordial por servirem de base para o cálculo da quantidade de água a ser aplicada, bem como o intervalo entre irrigações. A curva de retenção tem grande significação prática, mostra a relação rețenção-energia, de fundamental importância nos estudos de movimen to da água nos solos e sua absorção pelos vegetais.

Tradicionalmente a determinação da curva característica de umidade do solo é feito câmaras de pres são de Richards.

Recentemente FREITAS JR. e SILVA (1984), es tudaram o fatiamento de amostras centrifugadas, para determinação da curva de retenção da água no solo. Este método do ponto de vista prático, permite trabalhar com equipamentos simples e com alta produtividade. 
Em face dos aspectos discutidos o presente trabalho tem por objetivo avaliax, a funcionalidade do fatiamento de amostras centrifugadas, para determinação da çurva de retenção da água no solo, comparando-o com o método tradicional das câmaras de pressão de Richards. 


\section{REVISAO DE IITERATURA}

A água no solo encontra-se num determinado estado de energia, definido pelo que chamamos potencial total de áqua no solo, que é a somatória de diversos componentes conhecidos como gravitacional, osmótico, de pres são e matricial. Em condições isotérmicas e solo não satu rado, os potenciais de gravidade e matricial são os mais importantes. O potencial gravitacional é consequeencia da posição de um ponto em relação a um plano de referência, e o matricial é o resultado de forças capilares e de adsorção que surgem em razão da interação entre a água e a matriz do solo (REICHARDT, 1975).

SCARDUA (1984), diz que o potencial gravitacional assume maior importância quando o solo está próximo a saturação, porém, a baixos teores de água os poten ciais osmótico e matricial são efetivamente de maior inte resse.

o potencial matricial de uma amostra pode ser determinado experimentalmente através da câmara de pressão de Richarâs e funil de placa porosa (LIBARDI, 1984). O potencial osmótico é determinado pela equação de Van't Holf no entanto REICHARDT (1978) O considera desprezivel para solos não salinos. 
Os pesquisadores que se dedicam ao estuảo ligados aos aspectos da retenção de água no solo, tentam estabelecer relações entre a água retida no solo a um dado potencial e os fatores da mineralogia das partículas, como tamanho e natureza bem como o teor de matéria orgâni ca. GROHMAN \& MEDINA (1962) afirmam que a quantidade de á gua retida pelo solo é dependente do teor e natureza da fração argila e da porcentagem de matéria orgânica. Segun do SCARDUA (1972), a água retida a sucções relativamente baixas entre 0 a 1 bar, depende primeiramente do efeito da capilaridade e da distribuição do tamanho do poro e, sendo afetado pela estrutura do solo. Em tensões mais ele vadas, a retenção de água é devida a adsorção sendo $\therefore$ influenciada mais pela textura e superficie especifica do material do solo do que pela estrutura.

Reconhece-se dois pontos clássicos de umidade do solo: capacidade de campo e ponto de murchamento permanente que são de alta importância na prática de irrigação. A capacidade de campo corresponde à umidade atingida, sob conaições de campo, por solos permeáveis, de textura e estrutura uniforme, inicialmente saturados, anós sua drenagem livre ter ocorrido. COLMAN (1947), relatou que a utilidade da capacidade de campo como una caracteristica do solo aliada à dificuldade de sua determinação direta, proporciona uma reiação que pode ser facilmente determinada em labora tório. Segundo Colman, un pequeno boco de solo inicial mente saturado, drenado em uma placa porosa à tensão de 1/3 
de atmosfera, a umidade mesultante pode ser relacionada empiricamente com a capacidade de campo de alguns so Ios determinada sob condições naturais, e sugere que este procedimento pode ser um meio rápido de determinar indire tamente a capacidade de campo.

o ponto de murchamento permanente refere-se à umidade, no qual o solo não pode suprir as plantas de água em quantidades suficiente para manter a sua turgescência, e ela entra em murcha permanente, este ponto é classicamente considerado como a unidade dos solos correspondentes à tensão de 15 atm (RICHARDS \& WEAVER, 1943). Segundo VEIHMEYER \& HENDRICKSON (1949) a água compreendida entre estes dois Iimites, capacidade de campo e ponto de murchamento permanente, é definida como água dispoñivel e nele as atividadies biológicas da planta não seriam afetadas.

Embora COLMAN (1947), JAMISON \& KROTH (1958) tenham verificado que a tensão de 0,33 atm passa ser usada para indicar indiretamente o valor da capacidade de campo, outros pesquisadores têm usado tensões diferentes com resultados satisfatórios. Assim SALTER \& HAWORTH (1961) usaram 0,05 atm, e MACLEAN \& YAGER (1972) os valores de 0,05 e $0,1 \mathrm{~atm}$ como valores mais adequados. Sabe-se no entanto que a quantidade de àgua que permanece no solo é uma função do tamanho e do volume dos poros e portanto varia de acordo com a natureza do solo. Esta função é ysualmente redida esperinentalmente e é representada pela curva caracteristica de água no solo (WINTER, 1976). 
Assim, solos com diferentes aspectos de ta manho e natureza das particulas tem curvas caracteristicas diferentes.

A primeira tentativa utilizando a centrífuga em estudos de umidade do solo ocorreu com a introdu.ção do conceito de uridade equivalente. BRIGGS \& MCLiANE (1907), afirmaram que unia oase satisfatória para se compa rar a capacidade de retenção dos solos, poderia ser estar belecida pela quantidade de água que diferentes solos são capazes de reter quando esse solo está submetido a uma força constante, suficientemente em magnitude para remover a água retida nos espaços capilares maiores. Esses aul tores definem a umidade equivalente como a porcentagem de água água retida por um solo, quando a umidade é reduzida por meio de uma força centrî̀fuga constante, até que :ele entre num estado de equilíbrio capilar com a força aplica da.

Posteriormente, BRIGGS \& MCLANE (1910) padronizaram a definição de umidade equivalente propondo uma quantidade de solo àe 7 cm de espessura submetida “ à força de 1.000 vezes à graviáade durante 40 minutos a uma temperatura de $20^{\circ} \mathrm{C}$. A força centrifuga (f) expressa em dinas, agindo sobre um èlemento de ăgua (dm), é descrita como:

$$
f=4 \pi^{2} n^{2} r \cdot d m
$$

onde: $n$ = número de rotações por segundo; $r$ = cistāncia do eixo ao meio da amostra (cm); $\mathrm{dm}=$ é a massa de água infinitesinal em gramas. 
VEIHMEYER et alii (1924) e THOMAS e HARRIS (1925), no estudo da determinação de umidade equivalente através da centrifuga, questionaram quanto a exatidão do método. Os autores verificaram que arnostras mais finas de silte retinham menos água do que as amostras mais grossas do mesmo material. No mesmo estudo foi constatado que o tamanho das amostras tinha influência na por centagem de água retida e o tempo de centrifugação, para que as amostras atingissem o ponto de equilibrio, dependia da textura dos solos. Assim é que, as amostras de tex tura mais fina exigiam mais tempo para estabelecer o equi 1 íbrio.

GARDNER (1937) tentou calibrar a relação do potencial de umidade e o teor de água com papel de filtro úmido. o autor, basèado numa equação que expressa a força centrípeta com o gradiente do potencial de água em equilí brio na centrifuga, ou seja: $\psi_{1}-\psi_{2}=\frac{W^{2}}{2}\left(r_{1}^{2}-r_{2}^{2}\right)$, deter minou uma curva de calibração que foi usada posteriormente para estudar a tensão capilar abrangendo uma ampla fai xa de teores de água do solo, equilibrando-se o papel de filtro úmido com uma amostra de solo também úmida.

RUSSEL e RICHARDS (1938), usando um estudo similar ao de Garaner (1937), determinaram as relaçōes de energia da água do solo na centrífuga. o potencial capilar ( $\psi$ :, foi determinado aplicando a relação mencionada a seguir, isto é, $\frac{d \psi}{d r}=r^{2} r \ldots(1)$ 
onde: $r$ = distância do eixo da centrífuga ao meio da amos $\operatorname{tra}(\mathrm{cm})$;

$\mathrm{w}=\operatorname{velocidade}$ angular (rad. $\operatorname{seg} .-1)$.

Mantendo a velocidade angular constante, a equação (1) pode ser integrada entre os limites $r_{11}$ e $r_{2}$ ob tendo-se:

$$
\psi_{1}-\psi_{2}=\frac{w^{2}}{2}\left(r_{1}^{2}-r_{2}^{2}\right) \ldots
$$

Se $r_{1}$ representa a distância radial à superfície de água livre, $r_{2}$ à distância ao solo, então o $\left(\psi_{1}\right)$ ou potencial capilar na distância $r_{1}$ do centro de ro tação é zero. Na superfície onde a água é liberada ó seu potencial é zero. Assim o $\psi_{2}$, o potencial de capilaridade da água no solo torna-se, na equação (2):

$$
\psi_{2}=\frac{W^{2}}{2}\left(r_{2}^{2}-r_{1}^{2}\right)
$$

Nesse trabalho, a aplicabilidade da teoria é demonstrada determinando-se curvas de retenção para solos com textura arenosa e argilosa, através de centrífu-, gas com raios diferentes.

Com o advento das câmaras de pressão de RI CHARDS e FIREMAN (1943) e suas facilidades, as centrífugas for m relegadas a um segundo plano, provavelmente devide à dificuldades opeiacıonais ireientes as controle pre ciso da velocidade angular então existentes. 
ALEMI et alii (1976), aproveitando o gra- )

diente de potencial estabelecido na amostra durante a cen trifugação, descreveram um método usando amostras de solo centrifugadas, para determinar a condutividade hidráulica não saturada do solo. Em vez de usarem amostras finas, eles usaram amostras de $5 \mathrm{~cm}$ de extensão e $4,8 \mathrm{~cm}$ de diāmetro, coletados diretamente do campo. O potencial matricial e a distribuição de umidade ao longo da amostra após o equilíbrio numa determinada velocidade angular na centrîfuga, foram descritas matematicamente.

PANINGBATAN JR. (1980), seguindo a mesma linha de pesquisa de Alemi et alii (1976), utilizou pela primeira vez, o fatiamento de amostras centrifugadas. A curva de retenção da água no solo é obtida a partir da água retida e da distribuição do potencial da água ao longo da amostra. o potencial no ponto médio da amostra $(\bar{h})$ e a umidade $(\Theta)$ em cada operação foram usados para se estabelecer a curva característica. Este procedimento não é teoricamente correto.

FREITAS JR. e SILVA (1984); estudando o fa tiamento de amostras centrifugadas comparando com os méto dos tradicionais da câmara de pressão e da centrífuga mos traram a viabilidade cio método. No trabalho os autores propõem uma metodologia cie procedimerito de laboratório, pa ra deterrilnação da curva características da água no solo. 


\section{MATERIAL E MÉTODOS}

\subsection{LOCAL}

o experimento foi conduzido no laboratório de Física de Solos do Departamento de Engenharia Rural da Escola Superior de Agricultura "Luiz de Queiroz", em Piracicaba, São Paulo.

\subsection{SOLO}

o presente trabalho foi realizado em dois solos pertencentes, segundo Ranzani et alii (1966), às umidades taxonômicas Terra Roxa Estruturada Eutrófico textura franco argilosa (TRE) e Latossolo Vermelho Amarelo Distrófico textura franco arenosa (IVM), ou respectivamen te. Alfisol e Oxisol pela 7a Aproximagão do Soil Survey Staff (1975). 
Tabela 1 - Granulometria e classe Textural.

\begin{tabular}{lccccc}
\hline SOLO & $\begin{array}{c}\text { Profundidade } \\
\mathrm{Cm}\end{array}$ & $\begin{array}{c}\text { Areia } \\
\frac{0}{0}\end{array}$ & $\begin{array}{c}\text { Silte } \\
\%\end{array}$ & $\begin{array}{c}\text { Argila } \\
\frac{0}{0}\end{array}$ & $\begin{array}{c}\text { Classe } \\
\text { Textural }\end{array}$ \\
\hline TRE & $0-35$ & 33,9 & 27,5 & 38,4 & Franco argiloso \\
TRE & $35-55$ & 27,10 & 15,7 & 57,1 & Franco argiloso \\
$\mathrm{LVm}$ & $0-25$ & 83,0 & 1,2 & 15,6 Franco arenoso \\
$\mathrm{LVm}$ & $25-75$ & 75,6 & 7,8 & 16,5 Franco arenoso \\
\hline
\end{tabular}

\section{3. PIREPARAÇÃo das AMOSTRAS DO SOLO}

As amostras de solo foram coletadas à profundidade de $40 \mathrm{~cm}$, em cilindros de aluminio de $6 \mathrm{~cm}$ de comprimento e 4,8 cm de diâmetro interno.

Os cilindros foram cravados no solo por per cussão, em seguida foram levados com os devidos cuidados ao laboratório onde as amostras foram aparadas para as de terminações necessárias. As amostras foram protegidas na extremidade inferior com tecido perfex a fim de sustentar o solo, e colocadas dentro de uma bandeja com água para saturação. 


\title{
3.4. CURVAS DE RETENÇÃO DA ÁGUA NO SOLO
}

\author{
Foram determinadas as curvas de retenção \\ pela câmara de pressão de Richards e cela metodologia. \\ rroposta por Freita Jr. e Silva (1984).
}

3.4.1. DETERMINAÇAO DA CURVA DE RETENCẼ̃O, CONFORME MEIODOLOCIA ESIABETECIDA FOR RICHARDS (1943)

A curva de retenção dả água no solo foi oḅ tida por secamento, submetendo as amostras saturadas tensões seguintes.

: Em funil de placa porosa $(0,003$ e 0,006 MPa ) ;

- Em placa de Richards $(0,01 ; 0,03 ; 0,06$; 0,$1 ; 0,3 ; 0,6$ e $1,5 \mathrm{MPa}$.

Foram utilizadas amostras indeformadas coletadas em anéis de alumínio de $4,8 \mathrm{~cm}$ de diâmetro e 3,0 $\mathrm{cm}$ de altura. Estas amostras foram protegidas na parte in ferior do anel por tecido perfex preso com elástico de borracha.

As nostras foram saturadas durante 4i3 horas e submetidas às respectivas tensões, até que a drena- 
gem cessasse, o que se deu em aproximadamente 48 horas. Para cada tensão foram feitas três repetições. Foram determinados os valores de umidade gravimétricas e volumētricas, para cada tensão estudada.

\title{
3.4.2. DETERMINAÇÃO DA CURVA DE RETENÇÃO USANDO O FATIAMENTO DE AMOSTRAS CENTRIFUGADAS
}

\begin{abstract}
A centrífuga usada foi a "International Cen trifugue" (Model - M.E.) (Figura 1).

Para a realização desse trabalho, foi necessária uma adaptação de quatro peças de madeira de mes mo peso na centrífuga para permitir o balanceamento do tam bor e condicionar quatro locais para colocação das amostras, conforme ilustra a Figura 2. Nos locais das amostras foram colocados quatro cilindros de alumínio de $4 \mathrm{~cm}$ de comprimento para reduzir o raio de centrifugação das a mostras.
\end{abstract}

Para a realização de cada teste, quatro $\mathrm{c} \underline{\mathrm{i}}$ lindros com amostras de solo previamente saturadas e pesa das, eram colocadas na centrífuga com as amostras distribuidas de modo a obter um balanceamento equilibrado.

Cada cilindro df, amostra ao ser colocado na centrífuga tinha numa das extremidades uma tela filtran te a de açö inoxidável acoplada com papel de fil 
.15 .

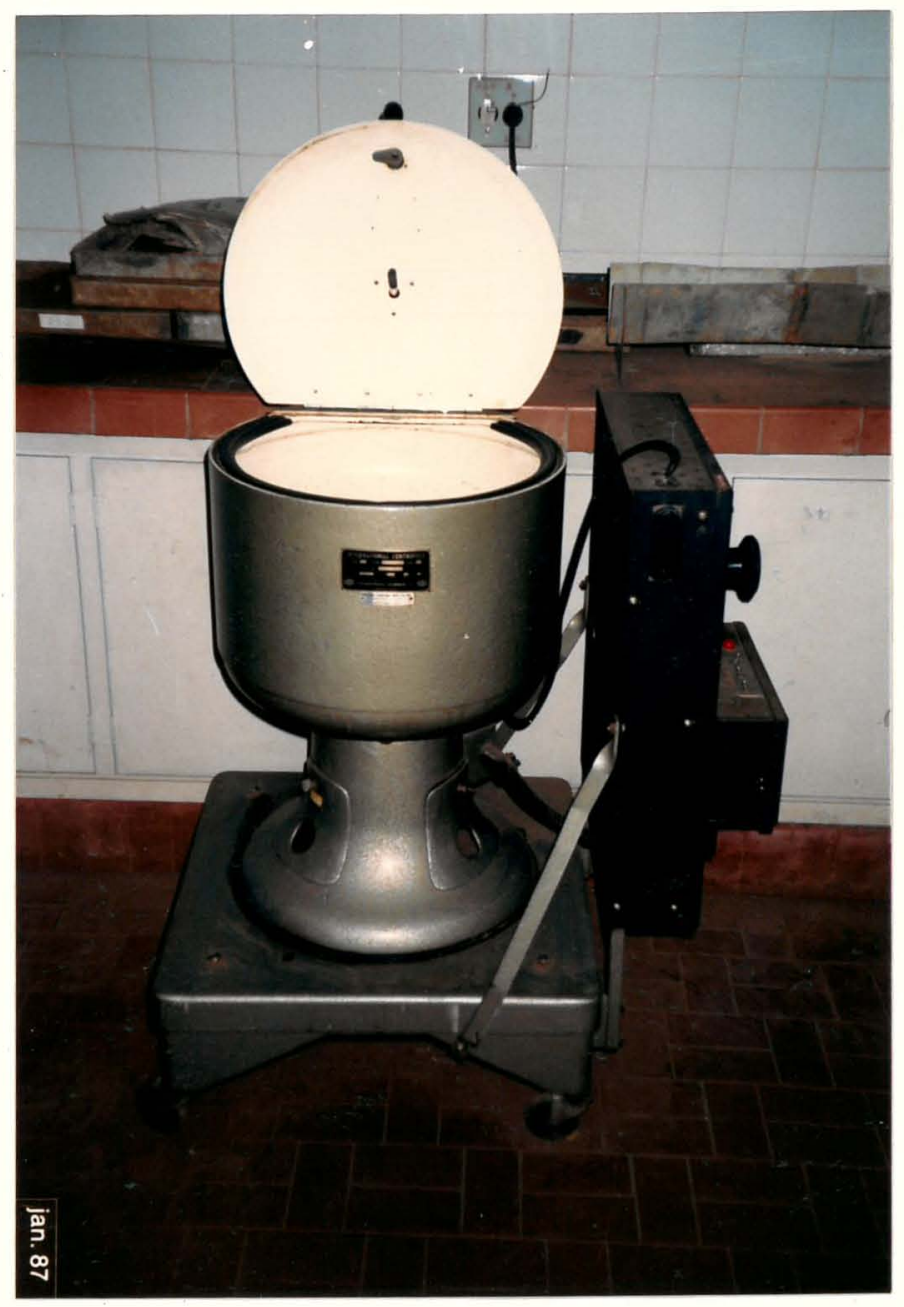

Figura 1 - Centrífuga - (Model. M. E.) 
.16 .

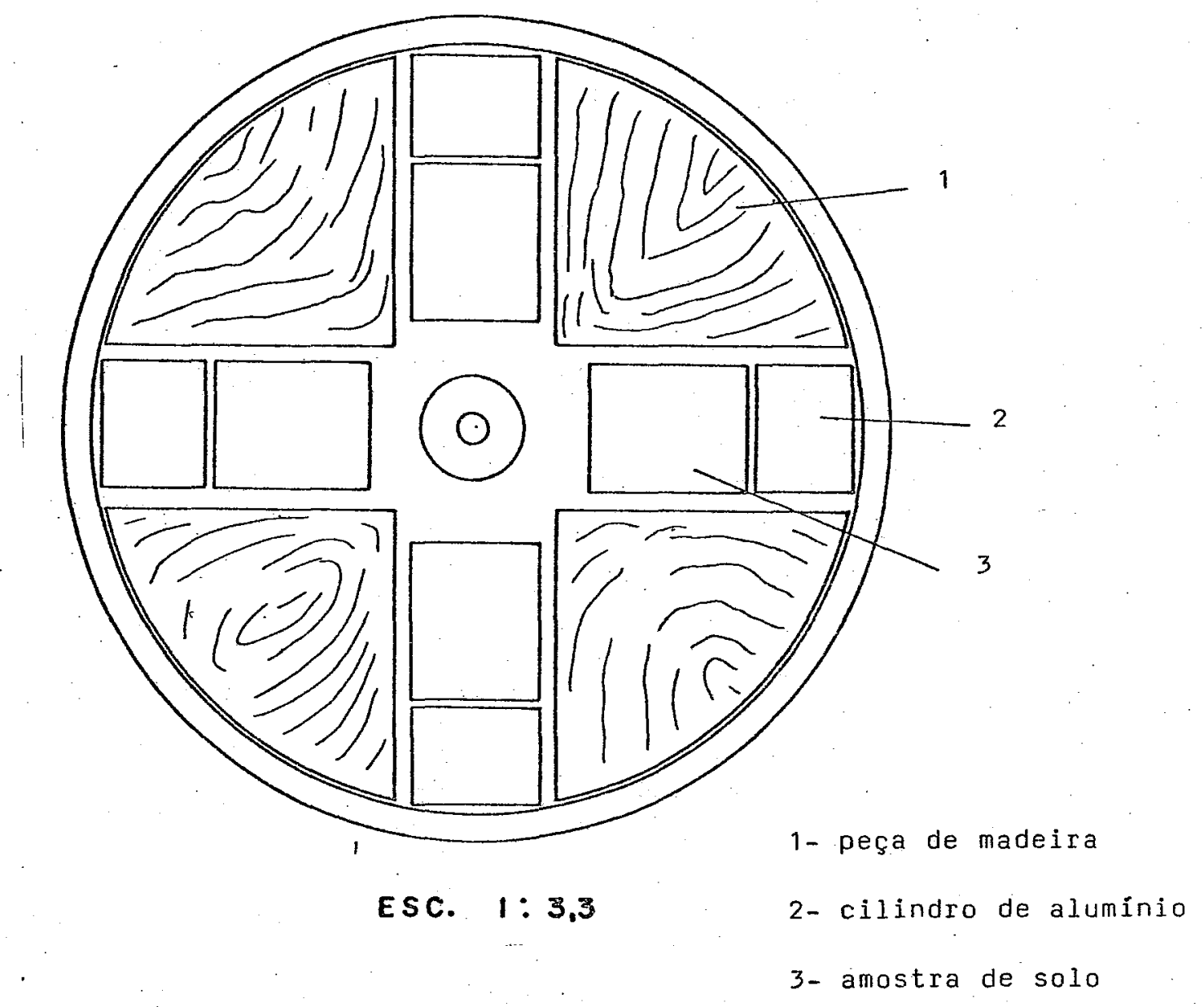

Figura 2. Esquema de distribuição das amostras no tambor da centrifuga e as respectivas peças de madeira. 
tro para condicionar a drenagem e na extremidade oposta e ra fechada com uma tampa de alumínio, para evitar a ocorrência de evaporação.

As amostras de solo eram então submetidas à centrifugação, a uma velocidade angular désejada de modo a desenvolver os potenciais desejados. O excesso de água era drenado para o exterior da amostra através da tela filtrante existente.

Durante a centrifugação observou-se que a velocidade angular variava um pouco, por isso utilizou-se durante o teste um "Tacômetro" para que houvesse um bom ajuste da velocidade angular. .

As amostras saturadas eram submetidas à cen trifugação por um intervalo de tempo de $30,60,120,180$, $240,300,330$ minutos às rotações de $720,1000,1400,1800$ e $2200 \mathrm{rpm}$ para o solo Terra Roxa Estruturada. Para cada rotação foi levantada uma curva para verificar qual o tem po necessário para que cessasse a drenagem, isto é, quando a energia da água do solo estava em equilíbrio com a e nergia produzida pela centrifugação. Este controle foi feli to pela determinação da umidade do solo em cada tempo. Com este procedimento determinava-se o tempo de centrifugação mínimo.

o mesmo procedimento foi feito para o solo Latossolo Vermelho Amarelo, mas as velocidades angular:s neste caso foram $72 \mathrm{~J}, 1.400,1.800$ e $2.300 \mathrm{rpm}$. 
Para cada velocidade angular usada no teste, foram feitas três repetições. Em cada teste eram colo cadas 4 amostras e submetidas a centrifugação até que o teor de água do solo atingisse o equilíbrio, isto é, cessasse a drenagem. Atingido o equilíbrio, eram retiradas du as amostras da centrífuga e as outras duas amostras perma neciam centrifugando para evitar a redistribuição deágua. As amostras retiradas da centrífuga eram imediatamente pe sadas, e uma dessas amostras era submetida ao fatiamento, com auxĩlio de um extrator hidráulico (Figura 3). A espes sura, com auxílio de uma espátula. Com este procedimento eram obtidas 3 subamostras que eram pesadas e levadas à estufa à $105^{\circ} \mathrm{C}$ para secagem.

A outra amostra era pesada e levada à estú fa à $105^{\circ} \mathrm{C}$ para secágem, com o objetivo de determinar a curva de estabilidade, curva esta que indicava a drenagem completa. Terminada esta operação, fazia o mesmo procedimento para as duas amostras que ficavam centrifugando.

De posse dos dados obtidos na estufa, foi determinada a umidade com base na massa do solo sexa em estufa de acordo com:

$$
\mathrm{U}=[(\mathrm{mu}-\mathrm{ms}) / \mathrm{ms}] \times 100
$$

onde: $U=$ umidade com base na massa do solo seca $\left(\frac{\circ}{0}\right)$;

$$
\begin{aligned}
& \mathrm{mv}=\text { massa úmida }(\mathrm{g}) ; \\
& \mathrm{nsc}=\text { mass secr em estura a } 105^{\circ} \mathrm{C}(\mathrm{g}) .
\end{aligned}
$$


.19.

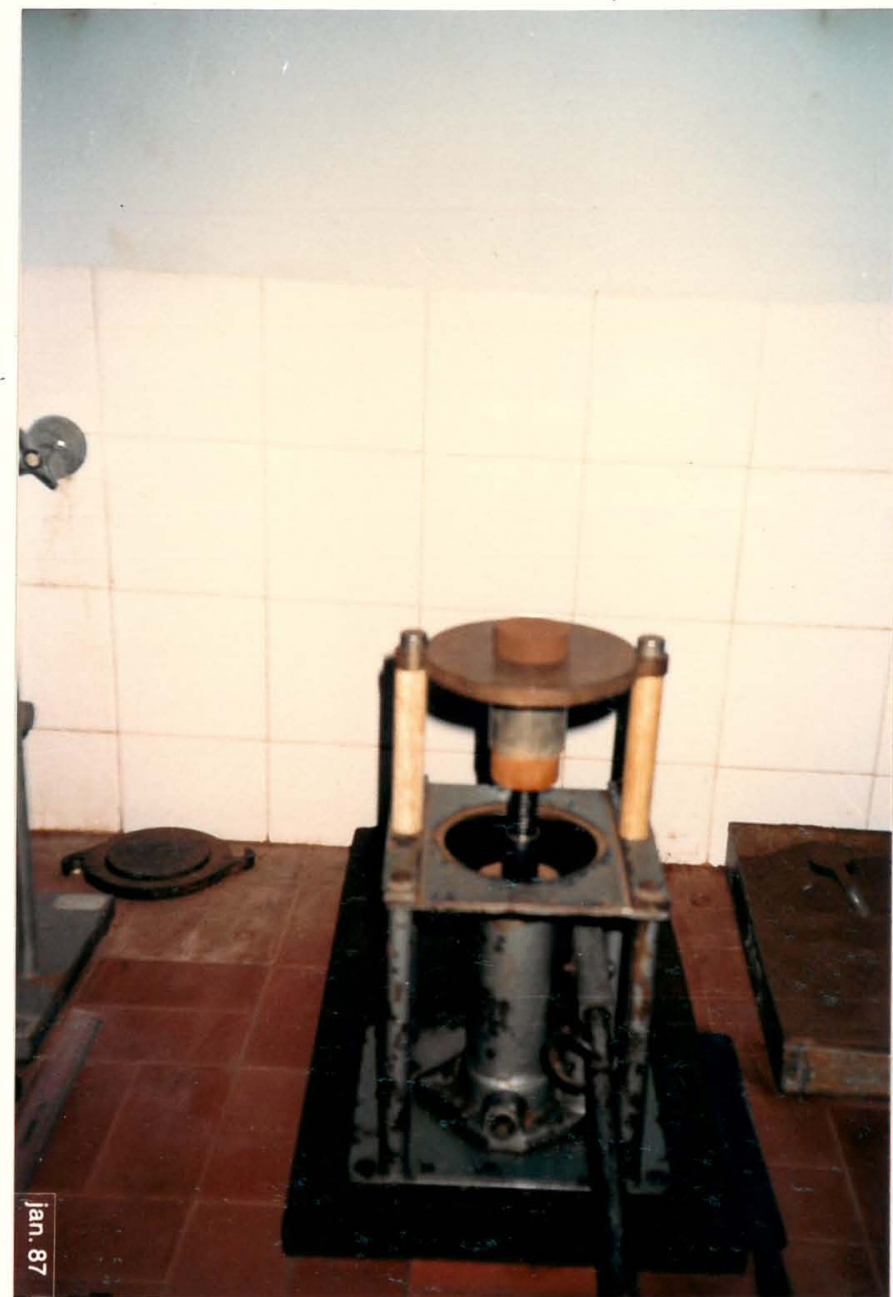

Figura 3 - Extrator hidráulico, utilizado no fatiamento das amostras. 
A determinação da denșidade global, que é essencial para se obter a umidade com base em volume, não foi determinada diretamente com as amostras fatiadas como era desejável, devido às perdas de solo ocorridas no fatiamento, e/ou quando ficavam impregnados na parede do $\mathrm{ci}$. lindro. Dada essa dificuldade, foram feitas várias determinações da densidade global para cada tipo de solo com a mostras submetidas à centrifuđạãa sem serem fatiadas e nas velocidades angulares desejadas, e foram feitas também determinações com amostras indeformadas coletadas diretamente no campo.

A densidade global foi obtida por meio da seguinte equaçãö:

$$
\mathrm{dg}=\mathrm{ms} / \mathrm{Vt}
$$

$$
\text { onde: } \begin{aligned}
\mathrm{dg} & =\text { densidade global }\left(\mathrm{g} / \mathrm{cm}^{3}\right) ; \\
\mathrm{ms} & =\text { massa seca em estufa a } 105^{\circ} \mathrm{C}(\mathrm{g}) ; \\
\mathrm{Vt} & =\text { volume do anel do cilindro }\left(\mathrm{cm}^{3}\right) .
\end{aligned}
$$

A curva característica de umidade das amostras submetidas a uma determinada velocidade angular $\underline{e}$ ra estabelecida conhecendo-se a distribuição do teor de água acima descrito e a distribuição do potencial médio ao longo da amostra. o potencial médio correspondente a cada ter. de água de cada fatia de amostra de solo, era calculáa pela equač̃o (12) descrita no modelo matemático desenvolvido por Freitas Jr. e Silva (1984). 


\subsection{MODEIO MATEMATICO}

o valor para o cálculo do potencial médio em qualquer camada de uma amostra de solo submetida à cen trifugação, foi obtido por FREITAS JR. e SILVA (1984). Es tes pesquisadores definiram que a centrifugação de uma amostra de solo, previamente saturada (Figura 4), gera um potencial matricial crescente ao longo do seu comprimento (de $r_{o} a r_{n}$ ). A relação entre este potencial, com a velocidade angular estabelecida e o raio da centrífuga são de finidos por:

$$
d \psi r=w^{2} \cdot g^{-1} \cdot r \cdot d r
$$

onde: $\psi r=$ potencial matricial da amostra na superfície em $r\left(\mathrm{~cm}\right.$ de. $\left.\mathrm{H}_{2} \mathrm{O}\right)$

$$
\begin{aligned}
\mathrm{w}= & \text { velocidade angular (rad.s } \left.\mathrm{s}^{-}\right) \\
\mathrm{g}= & \text { aceleração da gravidade }\left(\mathrm{cm} \cdot \mathrm{s}^{-2}\right) \\
\mathrm{r}= & \text { distância do eixo da centrífuga à superfície em } \\
& \mathrm{r}(\mathrm{cm}) .
\end{aligned}
$$

$$
\text { Integrando-se a eq. } 3 \text { no intervalo }\left(r, r_{i}\right)
$$

obtém-se que:

$$
\psi_{r}=\frac{1}{2} w^{2} g^{-1}\left(r^{2}-r_{i}^{2}\right)+\psi_{r i}
$$

onde: $\psi r_{i}=$ potencial matricial da amostra na superficie em $\mathrm{r}_{i}\left(\mathrm{~cm}\right.$ de $\left.\mathrm{H}_{2} \mathrm{O}\right)$

$r_{i}=$ distância do Eixo da centrifuga à superfície em $r_{i}(\mathrm{~cm})$. 


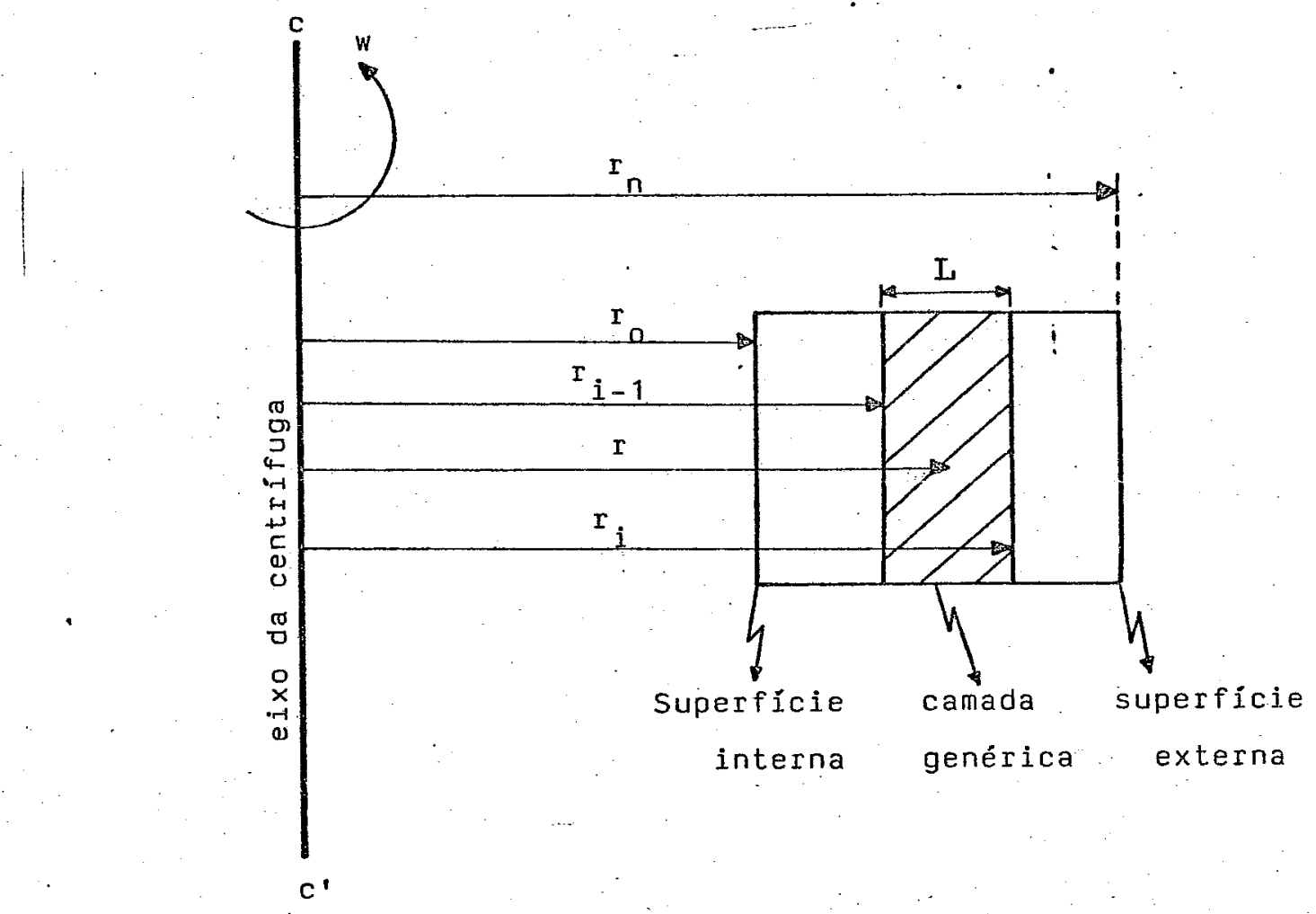

Figura 4. Represèntação esquemática de uma amostra na centrífuga. 
A equação 4 é a função que descreve a distribuição do potencial ao longo de $r$, até $r_{i}$.

o potencial matricial médio no intervalo $\left[r_{i}-1 ; r_{i}\right]$ da função $\psi_{r}$ é definido por:

$$
\bar{\psi}\left(r_{i-1}, r_{i}\right)=\frac{\int_{r_{i-1}}^{r} r_{d r}}{\int_{r_{i-1}}^{r} d r} .
$$

Aplicando a equação 4 na equação 5 , integrando e substituindo $\left(\dot{r}_{i}-r_{i-1}\right)$ por $L$, obtém-se:

$$
\ddot{\bar{\psi}}\left(r_{i-1}, \quad r_{i}\right)=\frac{1}{6} w^{2} g^{-1} L\left(L-3 r_{i}\right)+\psi r_{i}
$$

$$
\text { Reescrevendo-se a equação } 4 \text { para } r=r_{i-1}
$$

tem-se o potencial $\left(\psi r_{i-1}\right)$ na superficie $i-1$ :

$$
\Psi_{r_{i-1}}=\frac{1}{2} w^{2} g^{-1}\left(K_{i-1}^{2}-r_{i}^{2}\right)+\Psi_{r_{i}}
$$

Aplicando-se a equação 7 para a superfície em $i=n$ e considerando-se o potencial matricial na super fície em $\cdot r^{\prime \prime}$ ' por onde a água é liberada durante a centrifugação, igual a zero, obtém-se:

$$
\mathbb{L r}_{-1-1}=\frac{1}{2} w^{2} g^{-1}\left(\underline{n}_{n-1}^{2}-r_{n}^{2}\right)
$$

Para $i=n-1$, a equação 7 fica: 


$$
\psi r_{\bar{n}=2}=\frac{1}{2} w^{2} g^{-1}\left(\bar{r}_{n-2}^{2}-r_{n-1}^{2}\right)+\Psi r_{n-1}
$$

Aplicando-se a equação 8 na equação 9, che ga-se a:

$$
\begin{aligned}
\psi r_{n-2}= & \frac{1}{2} w^{2} g^{-1}\left(r_{n-2}^{2}-r_{n-1}^{2}\right)+\frac{1}{2} w^{2} g^{-1}\left(r_{n-1}^{2}-r_{n}^{2}\right) \\
& \text { simplificando-se, tem-se que: }
\end{aligned}
$$$$
\psi r_{n-2}=\frac{1}{2} w^{2} g^{-1}\left(r_{n-2}^{2}-r_{n}^{2}\right)
$$

Por indução, a partir da equação 8 e equação 10 , o potencial matricial na superficiegenérica $r_{i}$ fica definido pela seguinte equação:

$$
\psi r_{i}=\frac{1}{2} w^{2} g^{-1}\left(r_{i}^{2}-r_{i}^{p}\right)
$$

Aplicando-se a equação 11 na equação 6,0 potencial médio na camada delimitada por $\left[r_{i-1}, r_{i}\right]$ fica asism definido:

$$
\psi_{(x i-1-r i)}=\frac{1}{6} w^{2} g^{-1}\left[L\left(L-3 r_{i}\right)+3\left(r_{i}^{2}-r_{n}^{2}\right)\right]
$$

A equação (12) pode ser considerada a equação ge nérica para o cálculo do potencial médio $\left(\mathrm{cm}\right.$ de $\left.\mathrm{H}_{2} \mathrm{O}\right)$ em qualquer segmento de uma amostra centrifugada numa dada velocidade angular (rad. $\left.s^{-i}\right)$.

o cálculo da velocidade anguiar em rotações

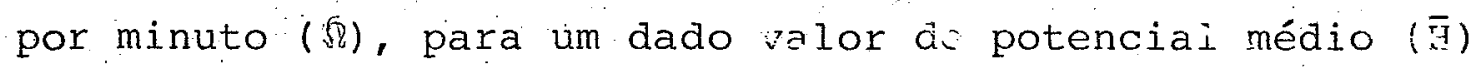


em atmosfera, pode ser obtido mais facilmente, reescreven do-se a equação 12 , da seguinte forma:

$$
\Omega=23.540\left\{\bar{H}\left(r_{i-1}, r_{i}\right) /\left[L\left(L-3 r_{i}\right)+3\left(r_{i}^{2}-r_{n}^{2}\right)\right\}^{1 / 2}\right.
$$




\section{RESUITADOS E DISCUSSATO}

\section{1. DENSIDADE GLOBAL (DG)}

A Tabela 2 mostra os valores da densidade global para cada solo e as respectivas velocidades de cen trịfugação. Observa-se que os valores da densidade são; em termos práticos, iguais independente da velocidade de cen trifugação. A densidade do solo sertãozinho é maior que a observada no solo Luiz de Queiroz, isto deve-se a textura arenosa do solo Sertãozinho enquanto o solo Luiz de Queiroz tem uma porcentagem maior em argila. Estes dados estão de acordo com aqueles observados por SCARDUA (1972).

\subsection{CURVAS DE ESTABILIZAÇAO DE UMIDADE DO SOLO}

As figuras 5 e 6 mostram os valores da umi dade obtidos na centrifugação das amostras dos solos TRE e LVm às velocidades especificadas. Com estes resultados consiruiran-se curvas de estabilização de umidade em fun ção do tempo de centrifugação. De acordo com elas observą -se que no solo Sertãozinho a e:tabilização foi atingia aos 180 minutos de centrifugação para todás as veiocidades, ao passo que o solo "Luiz de Queiroz" a estabiliza- 
Tabela 2 - Densidade global dos solos estudados

\begin{tabular}{|c|c|c|c|}
\hline Tipo de solo & & $\begin{array}{l}\text { lade global } \\
\left(\mathrm{cm}^{3}\right)\end{array}$ & $\begin{array}{l}\text { Amostras centrifugadas } \\
\text { em diferentes valores } \\
\text { de velocidade angular }\end{array}$ \\
\hline Sertãozinho & $\therefore$ & 1,63 & Diretamente do campo* \\
\hline Sertãozinho & & 1,64 & Centrifugà à $720 \mathrm{rpm}$ \\
\hline Sertãozinho & & 1,62 & Centrifuga à $1.400 \mathrm{rpm}$ \\
\hline Sertãozinho & & 1,64 & Centrifuga à $1.800 \mathrm{rpm}$ \\
\hline Sertãozinho & & 1,65 & Centrifuga à $2.300 \mathrm{rpm}$ \\
\hline Luiz de Queiroz & & 1,36 & Diretamente do campo: \\
\hline Luiz de queiroz & & 1,38 & Centrifuga à $720 \mathrm{rpm}$ \\
\hline Luiz de Queiroz & & 1,37 & Centrifuga à $1.000 \mathrm{rpm}$ \\
\hline Luiz de Queiroz & : & 1,35 & Centrifuga à $1.400^{\circ} \mathrm{rpm}$ \\
\hline Luiz de Queiroz. & & 1,39 & Centrifuga à $1.800 \mathrm{rpm}$ \\
\hline Luiz de Queiroz & & 1,37 & Centrifuga à $2.300 \mathrm{rpm}$ \\
\hline
\end{tabular}

* Amostras não submetidas à centrifugação. 


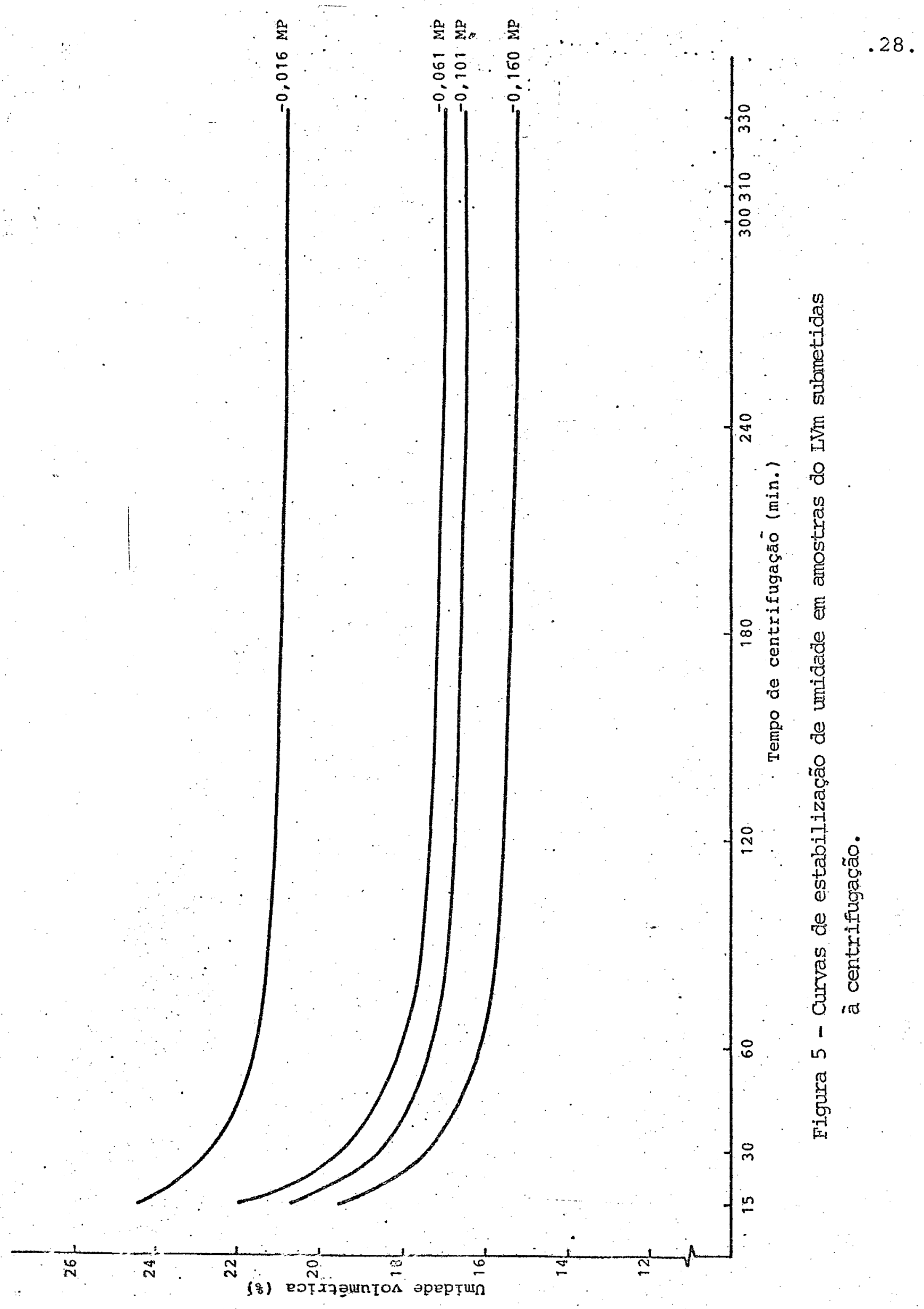




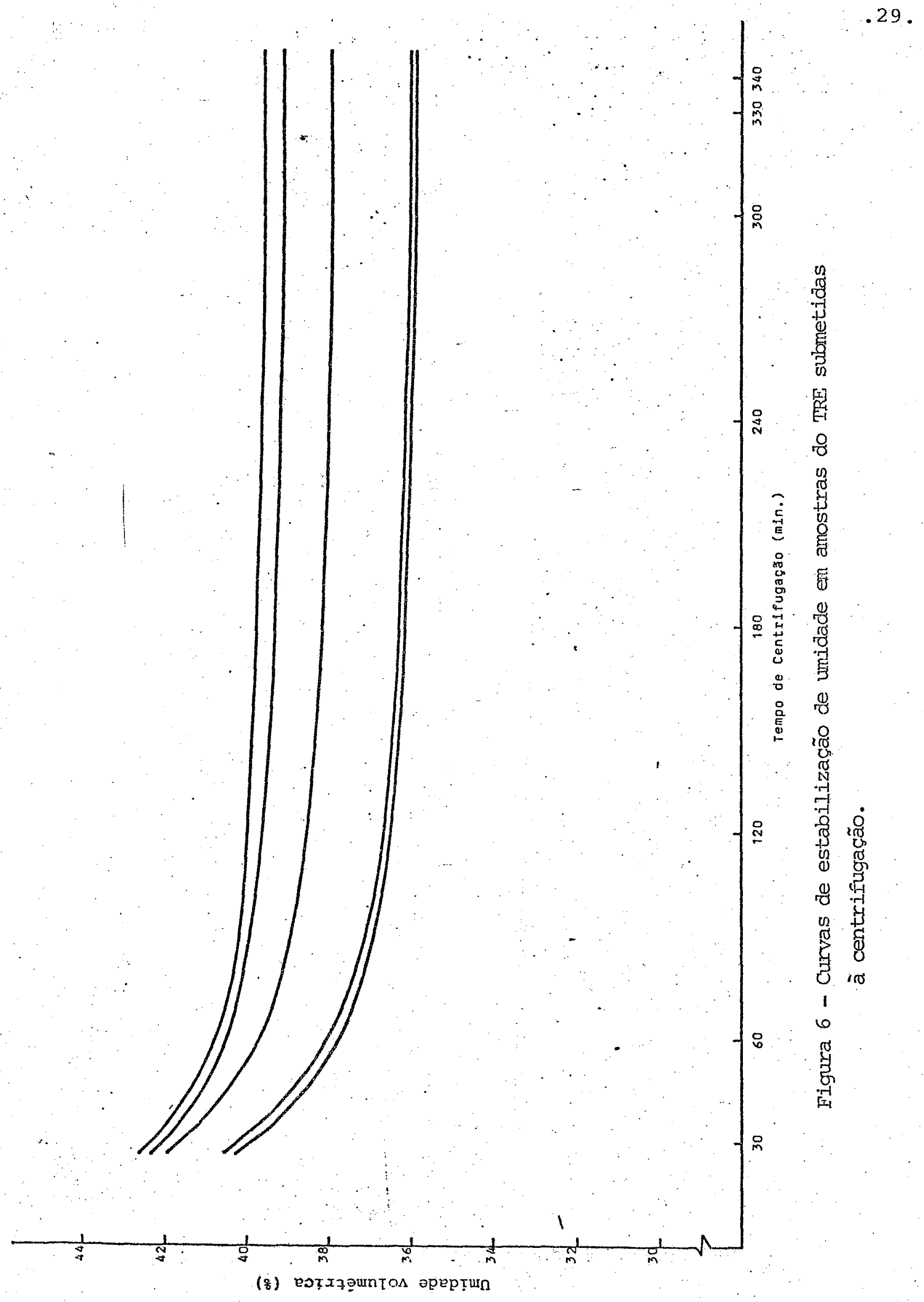


ção ocorreu aos 240 minutos. Esta diferença de tempo entre os dois solos se deve à textura, pois, o sertãozinho solo mais arenoso com maior porcentagem de macroporos (SCARDUA 1972), atingiu a estabilização em menor tempo, porquanto os grandes poros são esvaziados mais rapidamente em comparação aos poros menores.

Em ambos os solos estudados e de acordo com as curvas das figuras 5 e 6 pode-se observar que há um pa ralelismo entre elas, mostrando dessa maneira um comportá mento semelhante àqueles obtidos por FREITAS JR. \& SILVA (1984) em Latossolo Vermelho Escuro dos cerrados. Com estes resultados estabeleceu-se o tempo mínimo de centrifugação necessário para as determinações de umidade dos solos.

\title{
4.3. CURVAS DE RETENÇÃO DA ĀGUA NO SOLO
}

\subsubsection{CURVAS DE RETENÇÃO DA ÁGUA NO SOLO DETER- TERMINADAS NAS CÂMARAS DE PRESSÃO DE RI- CHARDS}

\begin{abstract}
A curva de retenção da água no solo depende, a ém de outros fatores, da textura e estrutura, is to é: do arranjo e das dimersões das partículas e dos poros. Em geral, quanto maior o teor de argila, mai-
\end{abstract}


or será o teor de água retida sob dada sucção. REICHARDT (1975). As Tabelas 3 e 4 mostram os valores médios do potencial matricial da àgua no solo, determinado com auxĩlio das cāmaras de pressão com amostras indeformadas. Com estes dados foram construidas as curvas de .. retenção da água no solo para os solos Terra Roxa Estruturada e La tossolos Vermelho Amarelo, conforme as Figuras 7 e 8 . Observa-se pelas curvas ơue as variações de umidade a baixas tensões são maiores no solo "Sertãozinho" em virtude deste solo apresentar uma ruaior macroporosidade em relacão ao solo "Luiz de Queiroz", pois é sabido que o incre-. mento de pequenas tensões em solo saturado os macroporos são facilmente esvaziados.

No solo "Luiz de Queiroz" com textura fran co argilosa, tem maior porcentagem de partículas de argila, com elevada superfície especifica e maior número de microporos, apresenta um decréscimo de umidade mais gradual e contínuo.

\subsubsection{CURVA CARACTERTSTICA DA AGUA DO SOLO DETER MTNADA NA CENTRTFUGA}

Os resultados do teor de água do solo em função do potencial matricial médio obtido para diferer.tes valores aje verocidade angular da centrifuga se encontram nas Tabelas 5 e $E$. Para cada velocidade angular foram 


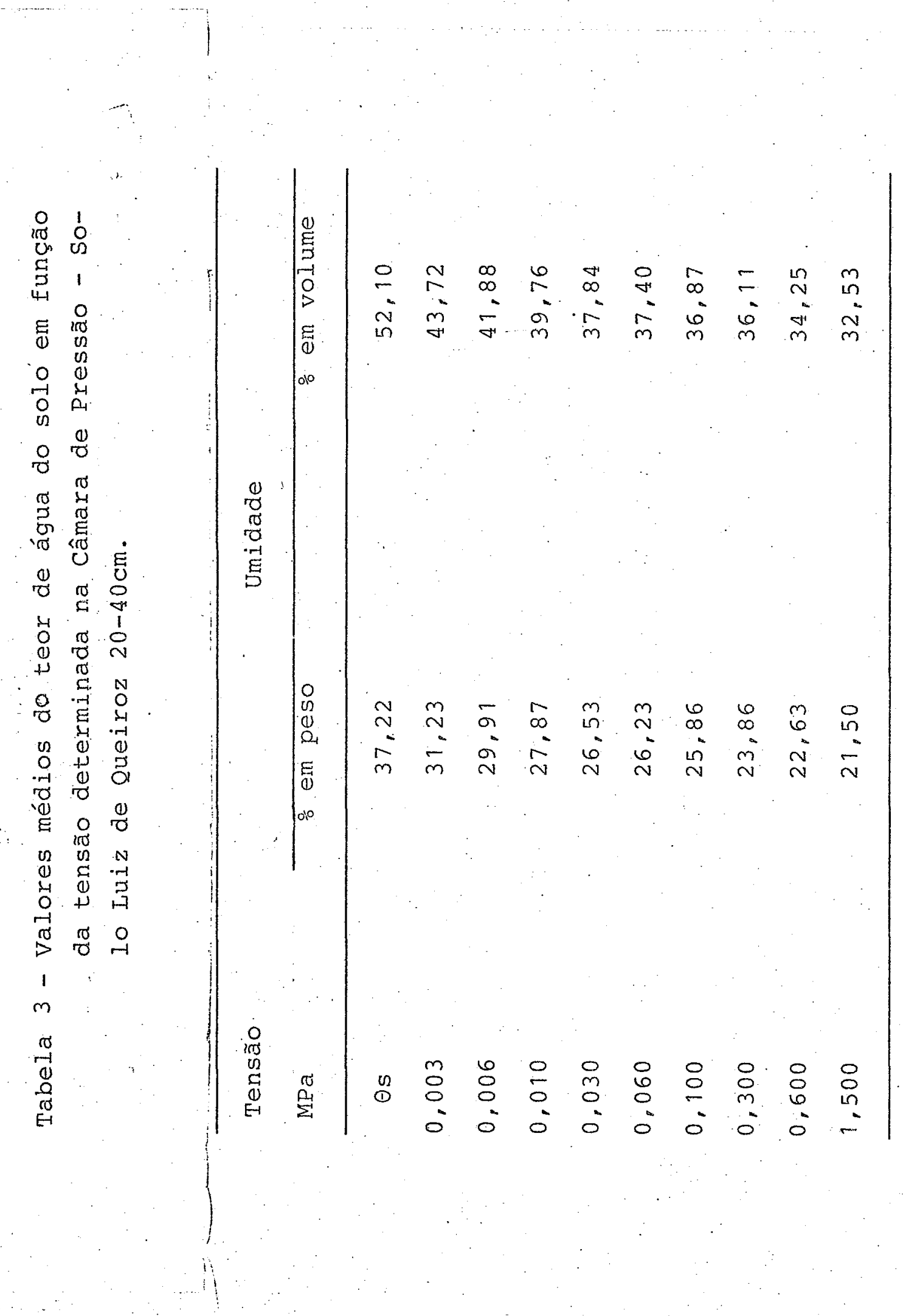




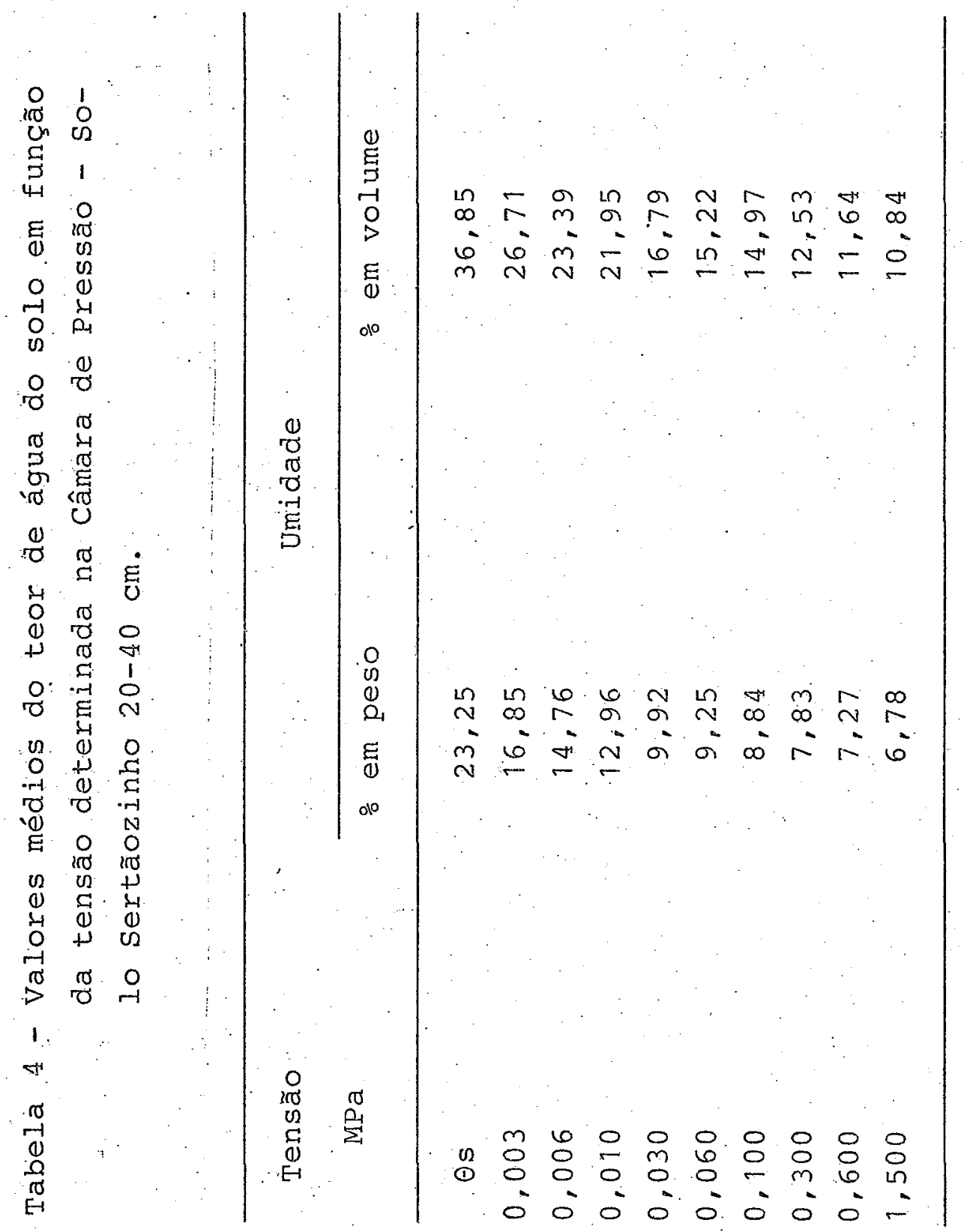




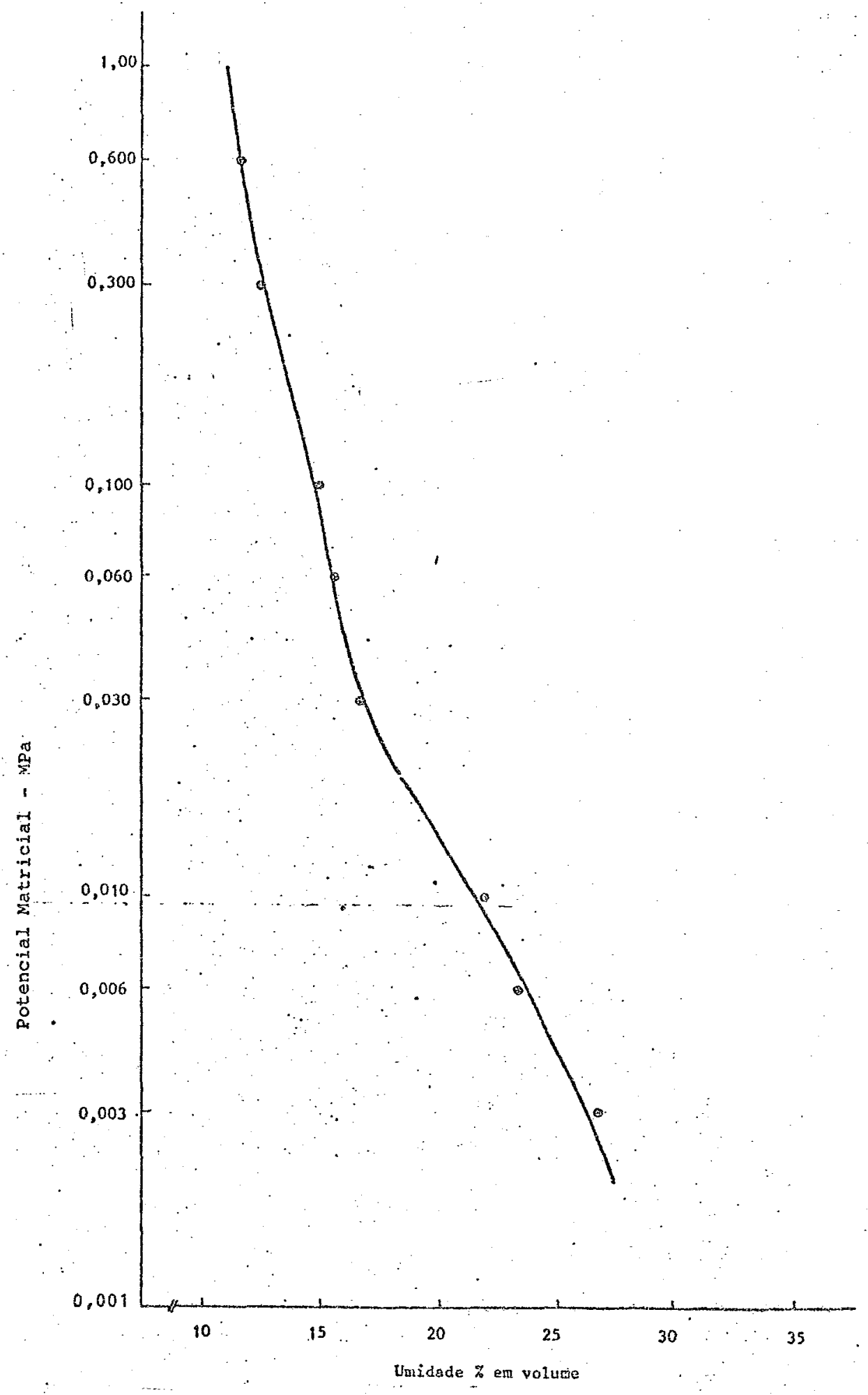

Figura 7. Curva de retenção da água no solo. Solo Sertãozisin. (20-4ucm). 


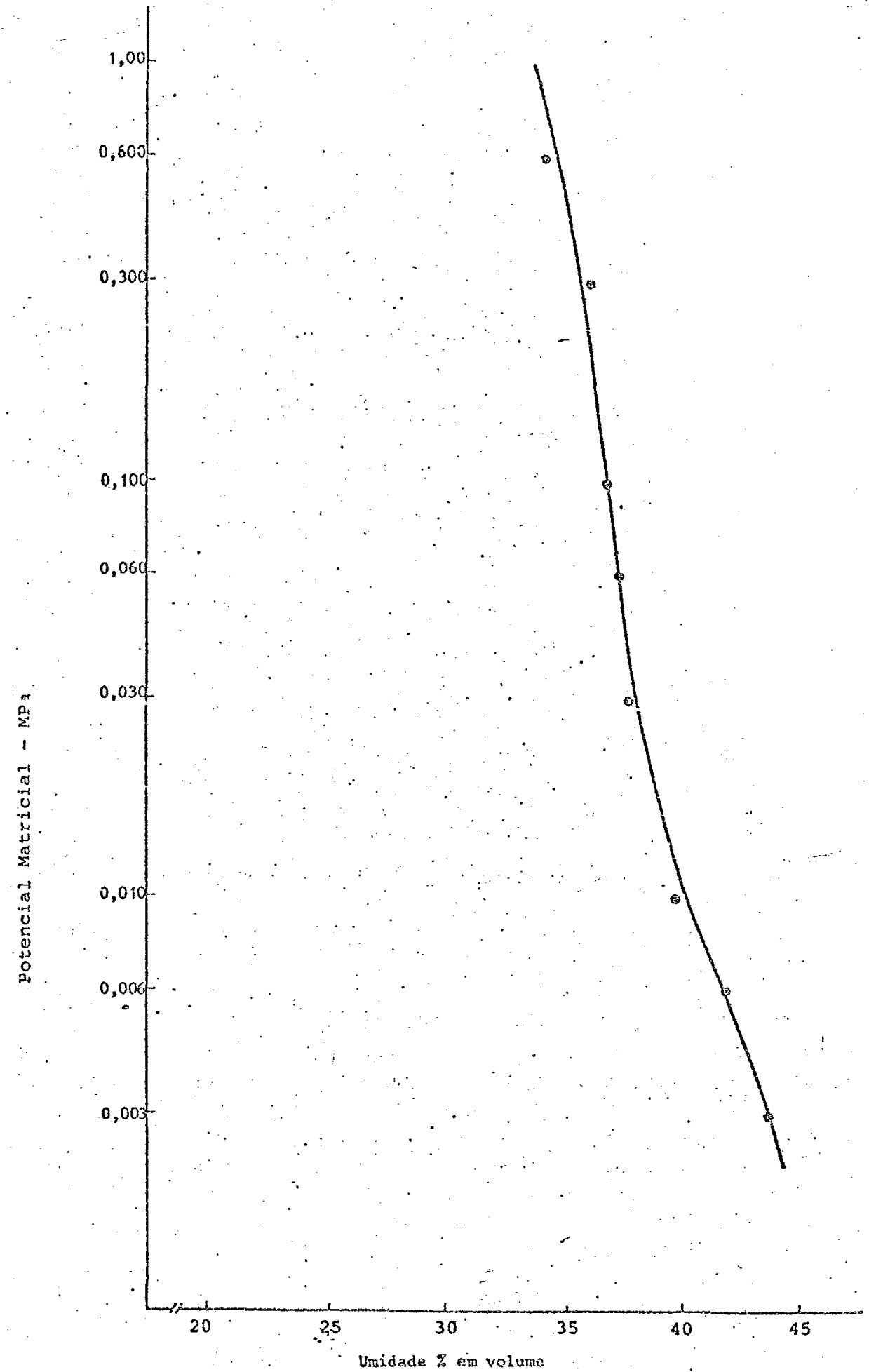

Figura 8. Curva de retenção da água no solo. Solo Iuiz de queiroz $(20-40 \mathrm{~cm})$. 
Tabela. - Valores médios do teor de áqua do solo em função do potencial médio calculados por camada, para diferentes valores de velocidade angular em uma centrifuga. com ro $=5,3 \mathrm{~cm}$. Para o solo "Luiz de Queiroz".

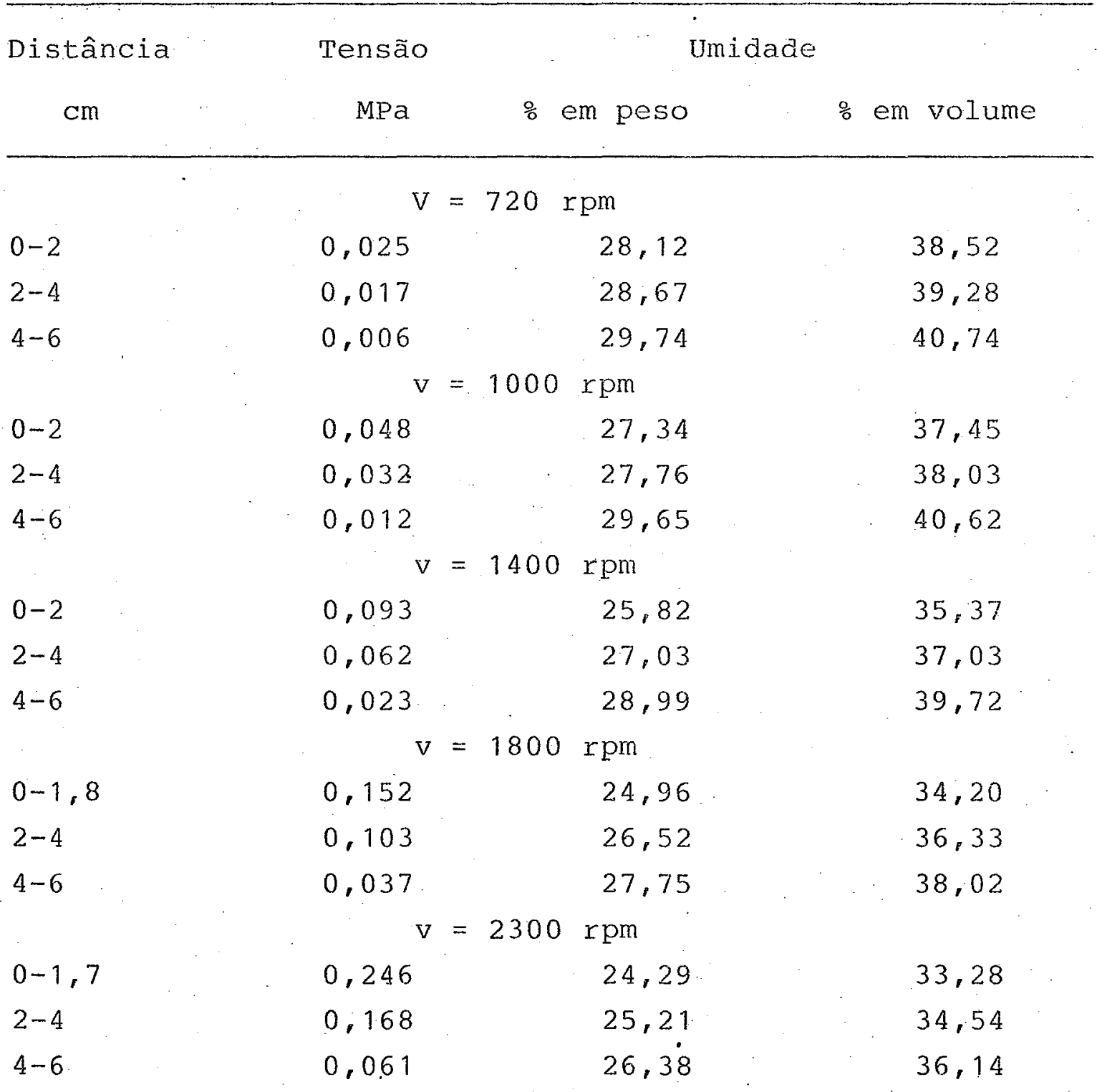


Tabela 6 - Valores médios do teor de água do solo em função do potencial matricial médio calculados por cama da, para diferentes valores de velocidade angular em uma centrífuga com ro $=5,3 \mathrm{~cm}$. Para o solo "Ser tãozinho" .

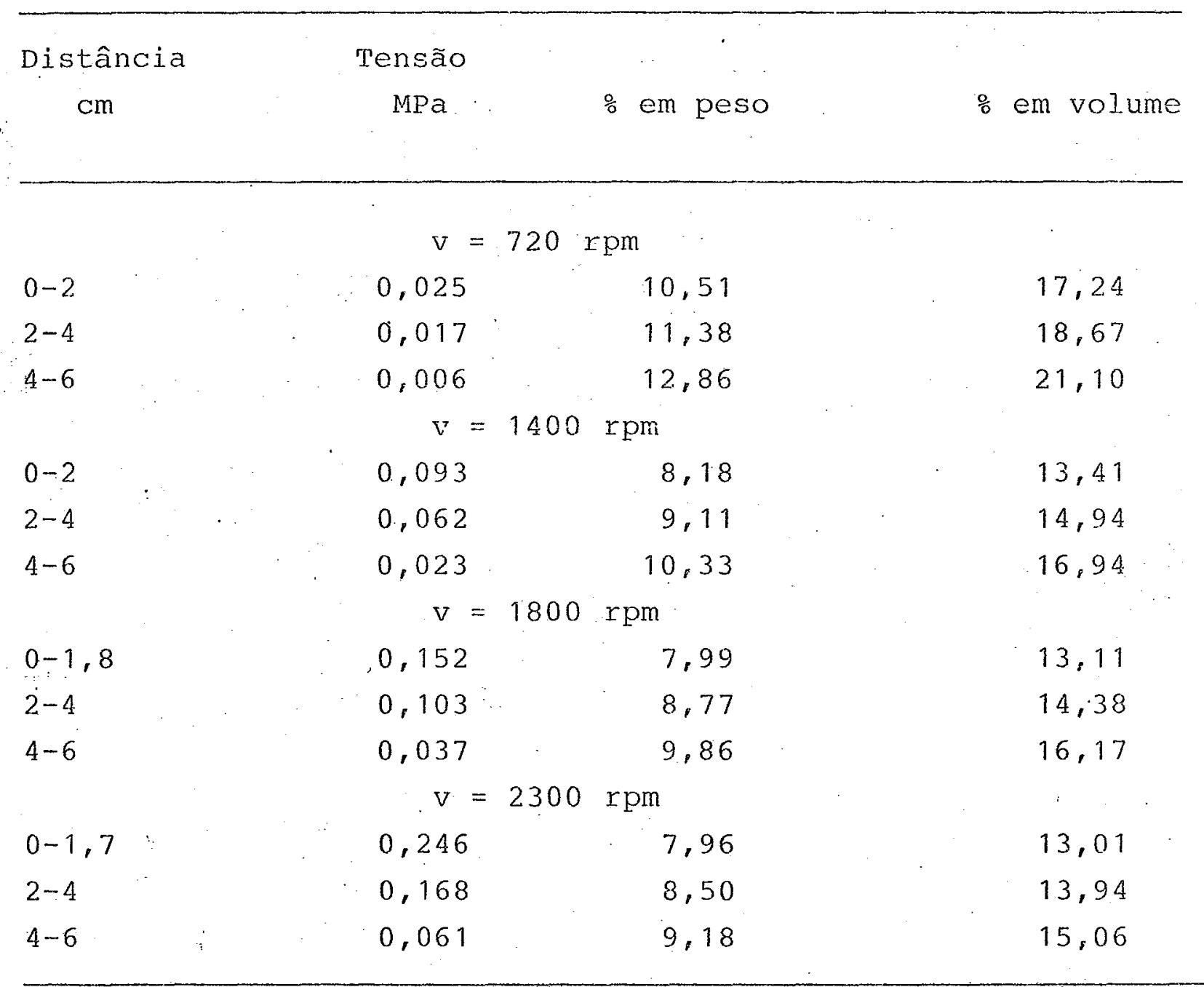


obtidos três valores de potencial matricial médio e as. respectivas umidades.

Em virtude das limitações da centrifuga para estudos desta natureza, não foi possivel estabelecer velo cidades angulares que permitissem alcancar potenciais matriciais desejáveis, isto é, valores abaixo daqueles cons tantes das Tabelas 5 e 6 , por isto o estudo ficou 1 imitado aos valores obtidos de acordo com as velocidades angulares de $720,1400,1800$ e 2300 r.p.m. para o solo "Sertãozinho" (LVm) e 720, 10000, 1400, 1800 e 2300 r.p.m. pa ra o solo "Luiz de Queiroz". (TRE). Em vista disto, não foi possivel caracterizar a água dos solos pela centrífuga en toda a extensão convencionalmente utilizada, ou seja, até 1,5 MPa de modo que se pudesse estabelecer uma re lação completa entre os resultados da centrifuga e das câ maras de pressão. Conforme Figuras 9 e 10.

Ponderando que, o propósito deste trabalho é verificar a precisão da centrîfuga na determinação do potencial matricial da água do solo, pode-se admitir gue os dados obtidos pela centrífuga são suficientes para con frontá-las com os dados obtidos pelas câmaras de pressão. 


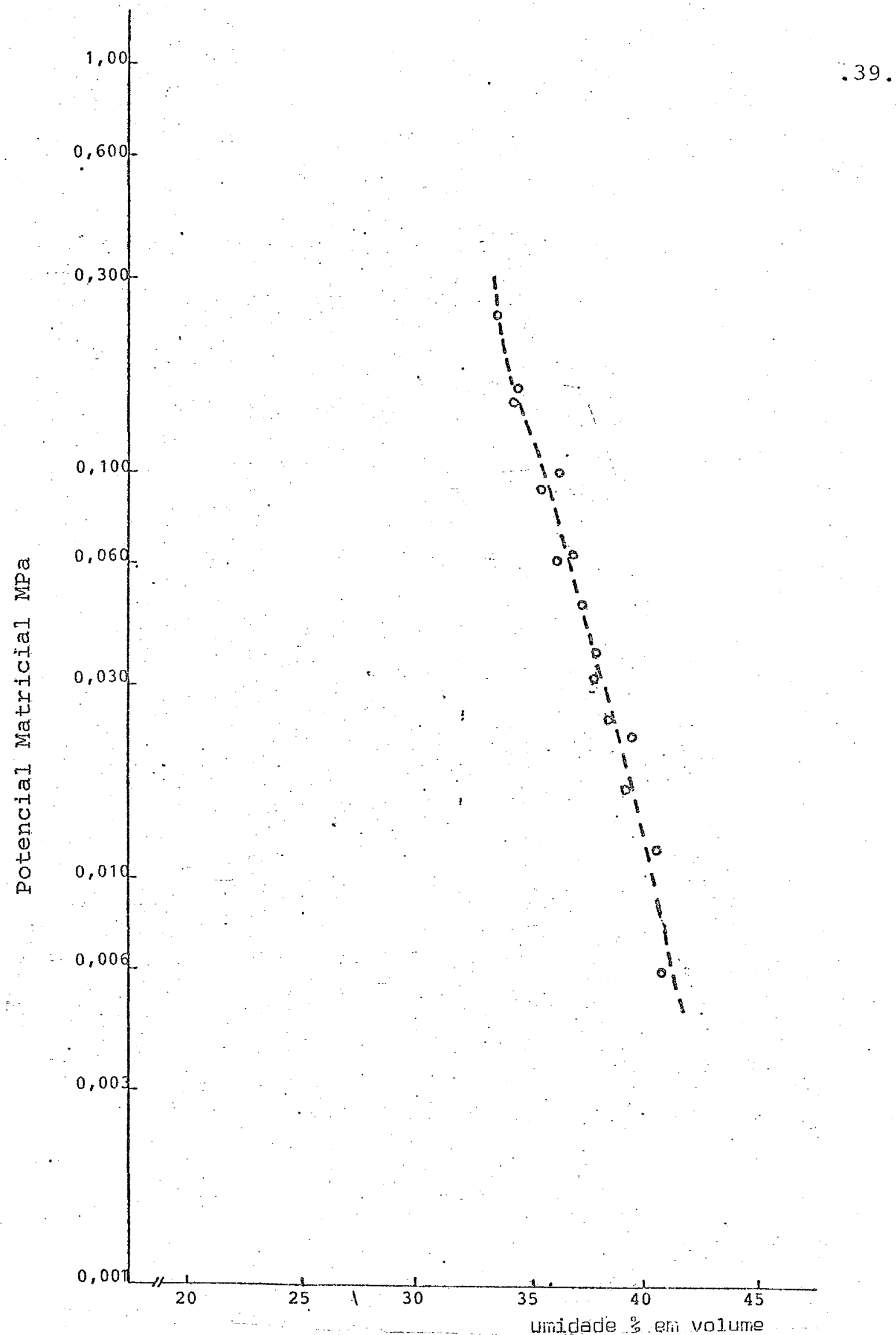

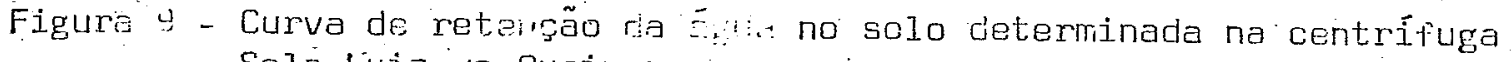
Solo luiz ve queiroz. 


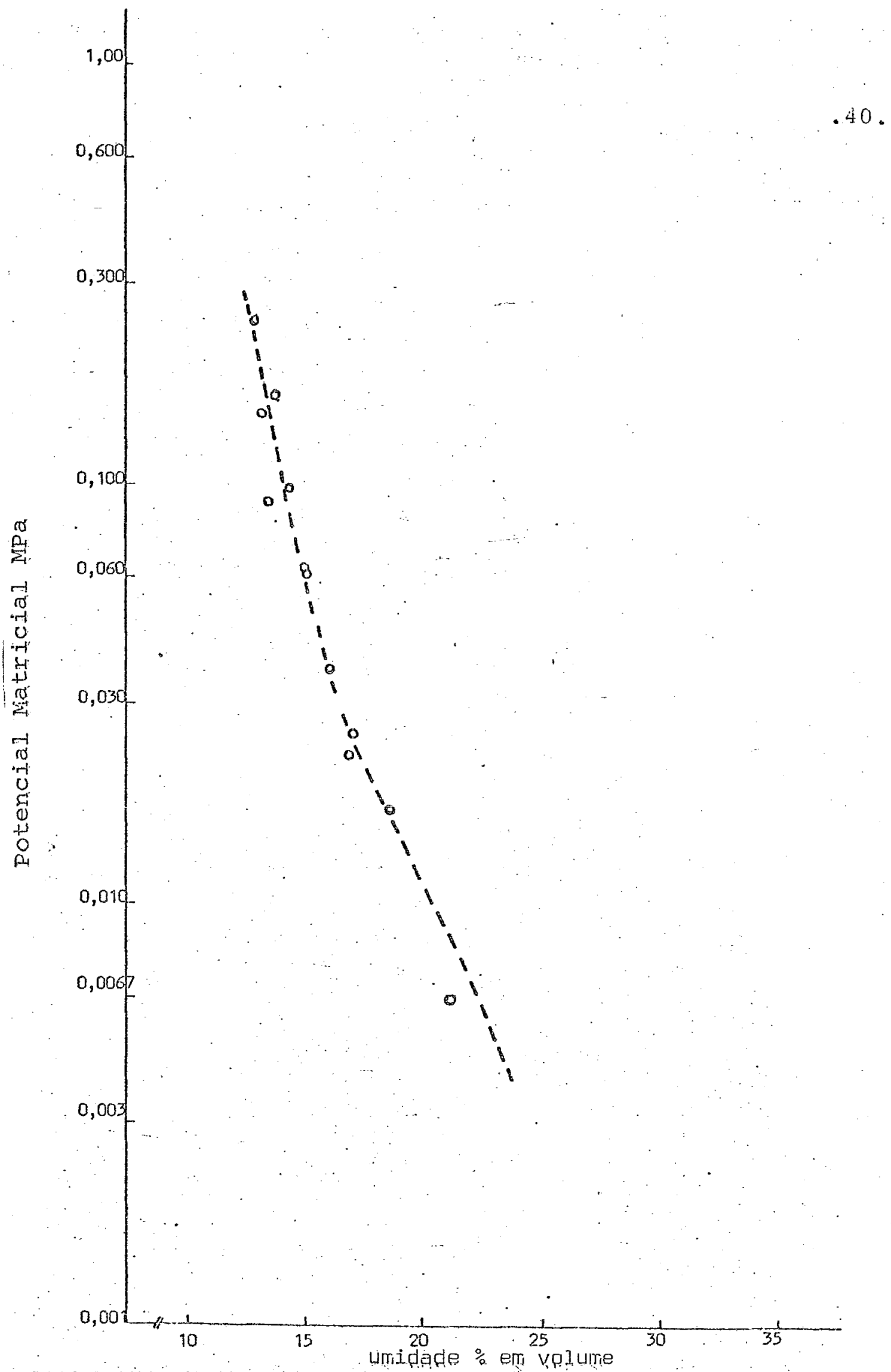

Figura 10 - . Curva de retenção da água no solo cieterminada na centrífuga. Solo Sertãozinho. 


\subsubsection{TRELAÇOES BNTRE AS CURVAS CARACTERISTICAS OBTTDAS PRTOS METODOS ESTUDADOS.}

As Tabelas $3,4,5$ e 6 mostram os valores dos potenciais matriciais da água no solo dos dois solos obtidos pelos dois métodos estudados.

As piguras 11 e 12 mostram as curvas de re tenção de cada solo, determinadas pelas câmaras de pressão e pela centrifuga.

No solo Luiz de Queiroz Figura 11 pode-se observar que a partir da tensão de $0,10 \mathrm{MPa}$ a curva obtida pela centrifuga tende a se afastar da curva obtida pelas câmaras de pressão. Este afastamento foi devido a cen trifugação, onde as amostras a altas rotações apresentavam ligeira compactação, e consequentemente um aumento da são e pela centrifuga.

No Solo Sertãozinho; Figura 12 observa - se que há um pequeno afastamento a baixas tensões ou seja à 0,006 MPa, pode-se atribuir este fato a ocorrência dá rápida redistribuição da água ao final da redistribuição da água no final da centrifugacão, pois, por se tratar de solo arenoso, com macroporos com alto teor de água, a mes ma se redistribui com certa rapidez. 


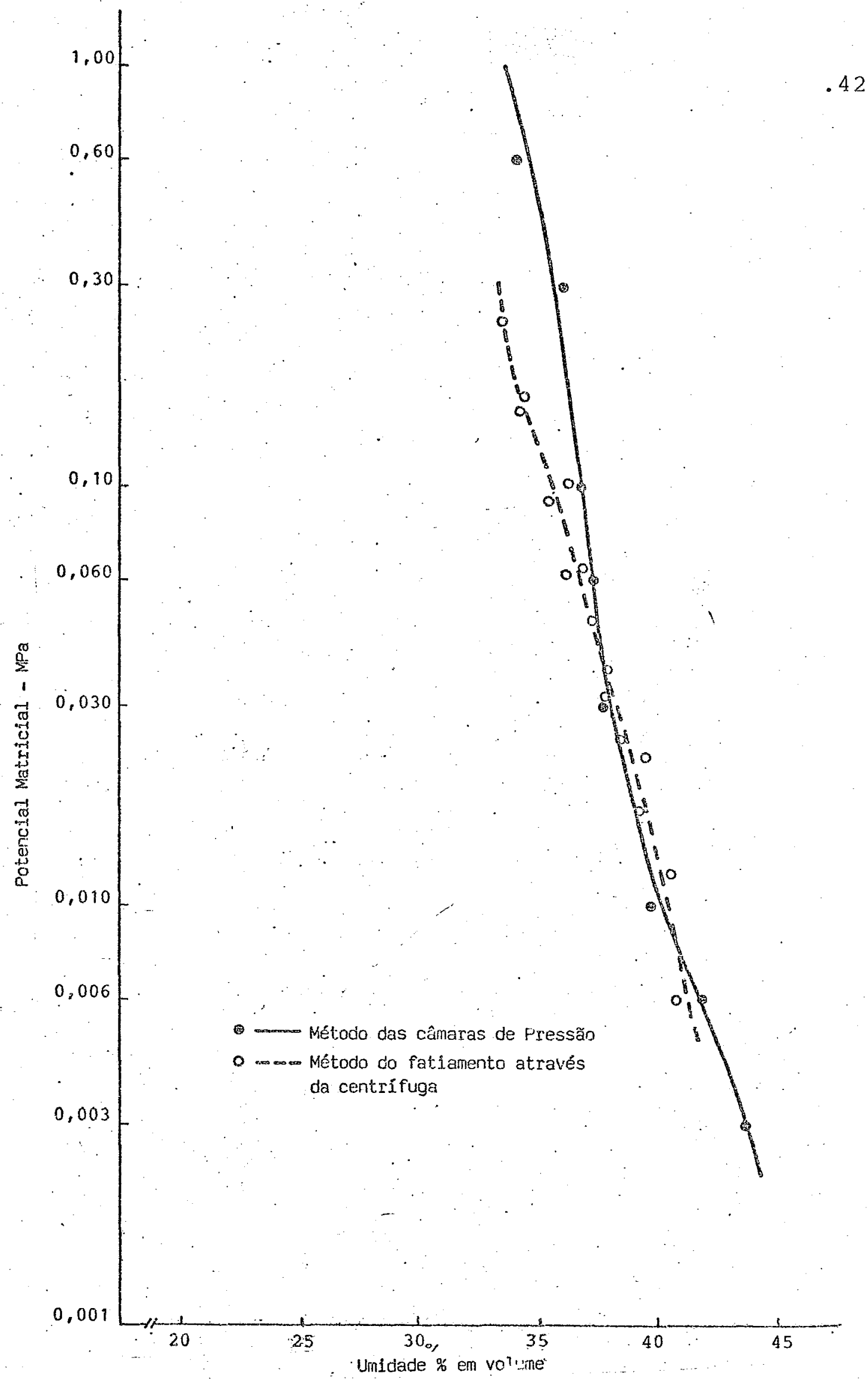

Figura 11 - Curvas de retenção da àcu no 5010 pelos métodos da reñ-

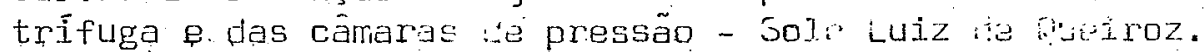




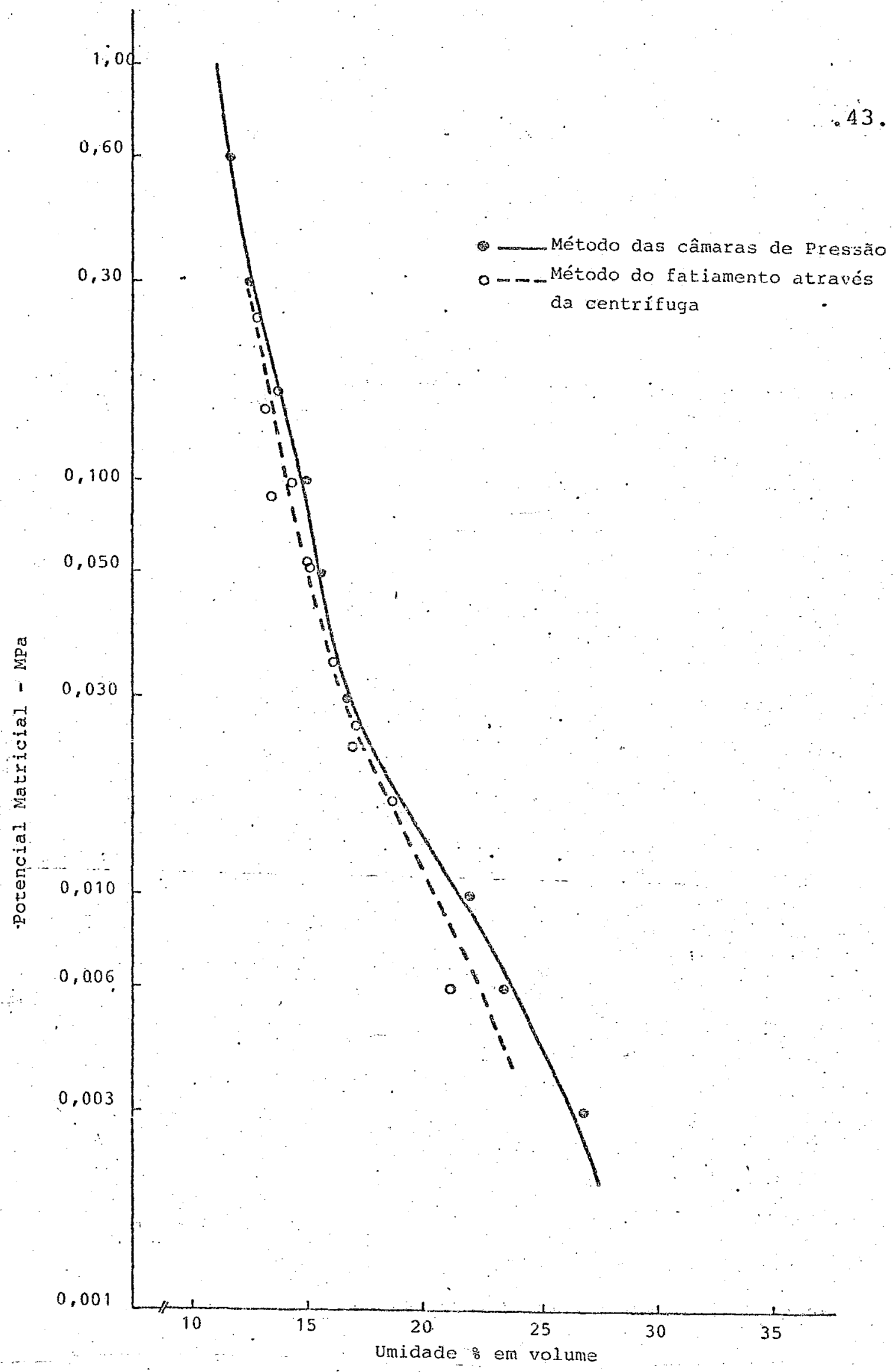

Figura 12 - Curvas de retengão da água ro solo, pelos métodos da cen-

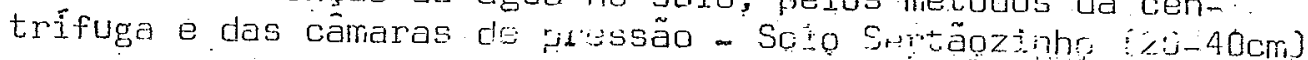




\subsection{CORRELACEO MNTRE OS MFIODOS ESTUDADOS PARA AMBOS OS SOLOS.}

\subsubsection{SOLO SERTAOZTNHO}

Para o estudo de correlação entre os métodos estudados foi feita uma análise de variância para a regressão linear, quadrática e cúbica conforme a Tabela 7. Observa-se que o melhor ajuste como era de se esperax foi a linear, significativo a nivel de 1\% de probabilidade com indice de correlação de $r=0,9716$.

Uma alta correlação não significa necessariamente que os dados de umidade em função da tensão são iguais ou estão próximos um do outro, esta análise apenas indica a corrèlação existente entre os dados confrontados. Para verificar se há coerência entre os resultados a Figura 13 mostra a curva que confronta as umidades determinadas pelos dois métodos e a respectiva equação, $\quad y=$ $-1,3114+1,1174 x$, onde $y$ é a umidade referente à câmara de pressão e x a umidade correspondente a centrífuga. Cada par de valores de umidade corresponde ao mesmo potencial matricial.

Para verificar a confiabilidade dos dados

foi feito um estudo de interval's de confiança segundo HOF FMANN e VIEIRA (1983) para a regressão linear. â. Figura 14 mostra um gráfico onde se pode verificar ustatistica- 
TABELA 7 - Análise da variância para os métodos estudados. Para o solo Sertãozinho.

\begin{tabular}{llllc}
\hline Causas de variação & GL & QM & $F^{\prime}$ \\
\hline & & & & \\
RL & 1 & 83,7921 & $168,545^{*} *$ \\
RQ & 1 & 2,1572 & $6,898^{*}$ \\
RC & 1 & 0,4069 & 1,352 \\
\hline
\end{tabular}

* Significativo ao nível de 5\% de probabilidade

* Significativo ao nivel de 1\% de probabilidade

TABELA 8 - Análise da variancia para os métodos estudados. Para o solo Juiz de Queiroz.

Causa de variação GL QM $\quad$ G

\begin{tabular}{rrrc}
$\mathrm{RL}$ & 1 & 25,4246 & $54,638 * *$ \\
$\mathrm{RQ}$ & 1 & 2,5421 & $8,698 *$ \\
$\mathrm{RC}$ & 1 & 1,6565 & $9,845 * *$ \\
\hline
\end{tabular}

*. Significativo ao nível de 5\% de probabilidade

* * Significativo ao nível de $1 \%$ de probabilidade 


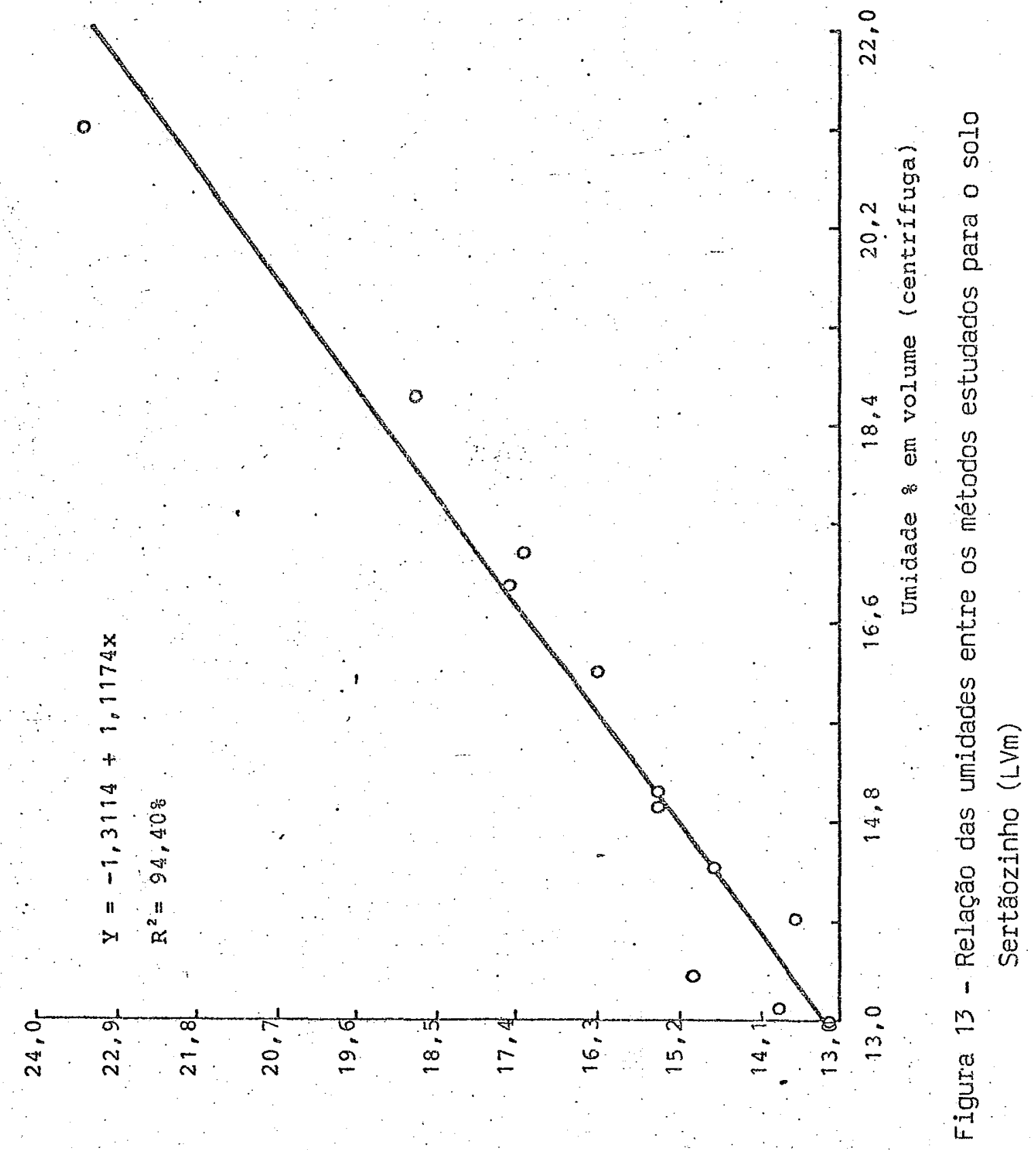

(opssaxd op exeupo) ountos wa 웅 e; eptrun 


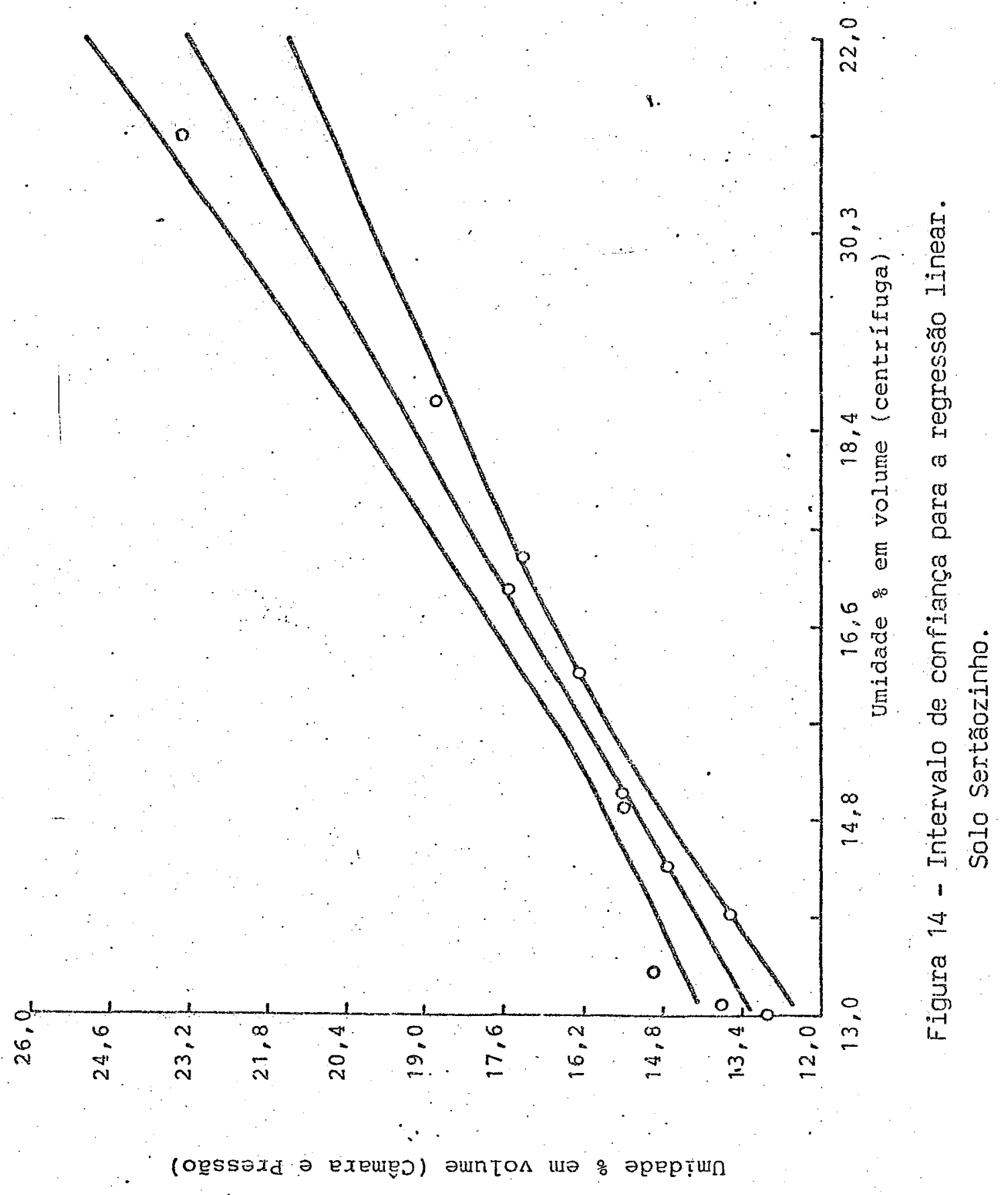


mente que todos os pontos estão dentro do intervalo de con fiança ao nivel de $99 \%$

\subsubsection{SOLO LUIZ DE QUEIROZ}

Para o solo "Luiz de.Queiroz" (TRE) aplicou-se o mesmo procedimento aplicado ao solo "Sertãozinho" (LVm). A Tabela 8 mostra a análise de variância para a regressão linear, quadrática e cúbica. Verifica-se que o melhor ajuste foi o linear, significativa ao nível de $1 \%$ de probabilidade com indice de correlação $r=0,8088$. Esta correlação foi mais baixa que a do solo:"Sertãozinho", em virtude do afastamento das curvas da Figura11, acima de $0,1 \mathrm{MPa}$, mais acentuado.

A Figura 15 mostra a curva que confronta os valores das umidades determinadas pelos dois métodos e a respectiva equação: $\mathrm{y}=16,1221+0,5836 \mathrm{x}$ onde $\mathrm{y}$ é a umidade determinada nas câmaras de pressão e $\mathrm{x} a$ umidade correspondente à centrífuga.

A Figura 16 mostra o intervalo de confian-: ça, segundo HOFFMAN \& VIEIRA (1983) para regressão linear. Pela Figura 16 pode-se verificar estatisticamente que todos os pontos estão dentro do intervalo de confiança ao nível de $99 \%$. 


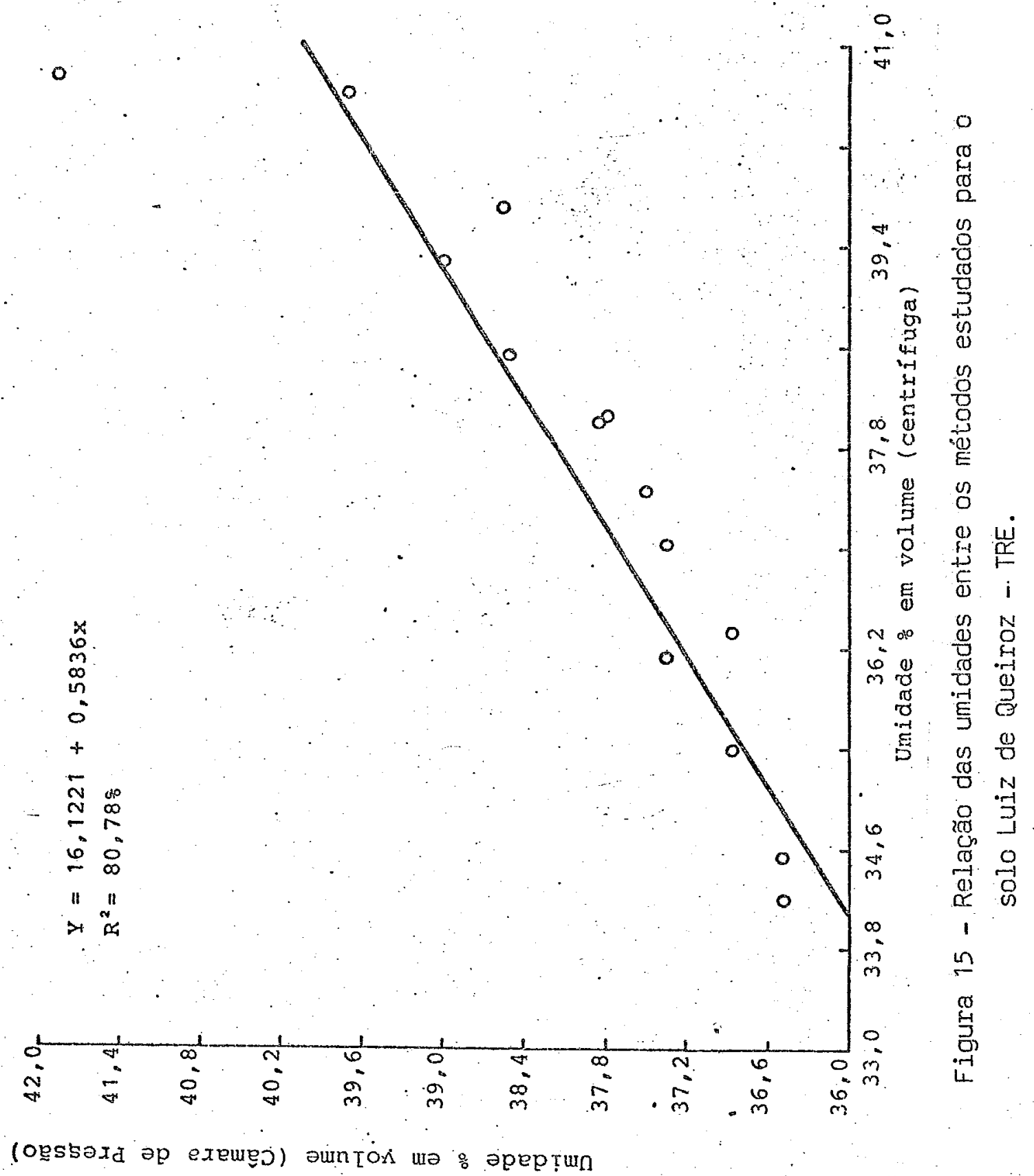


.50.

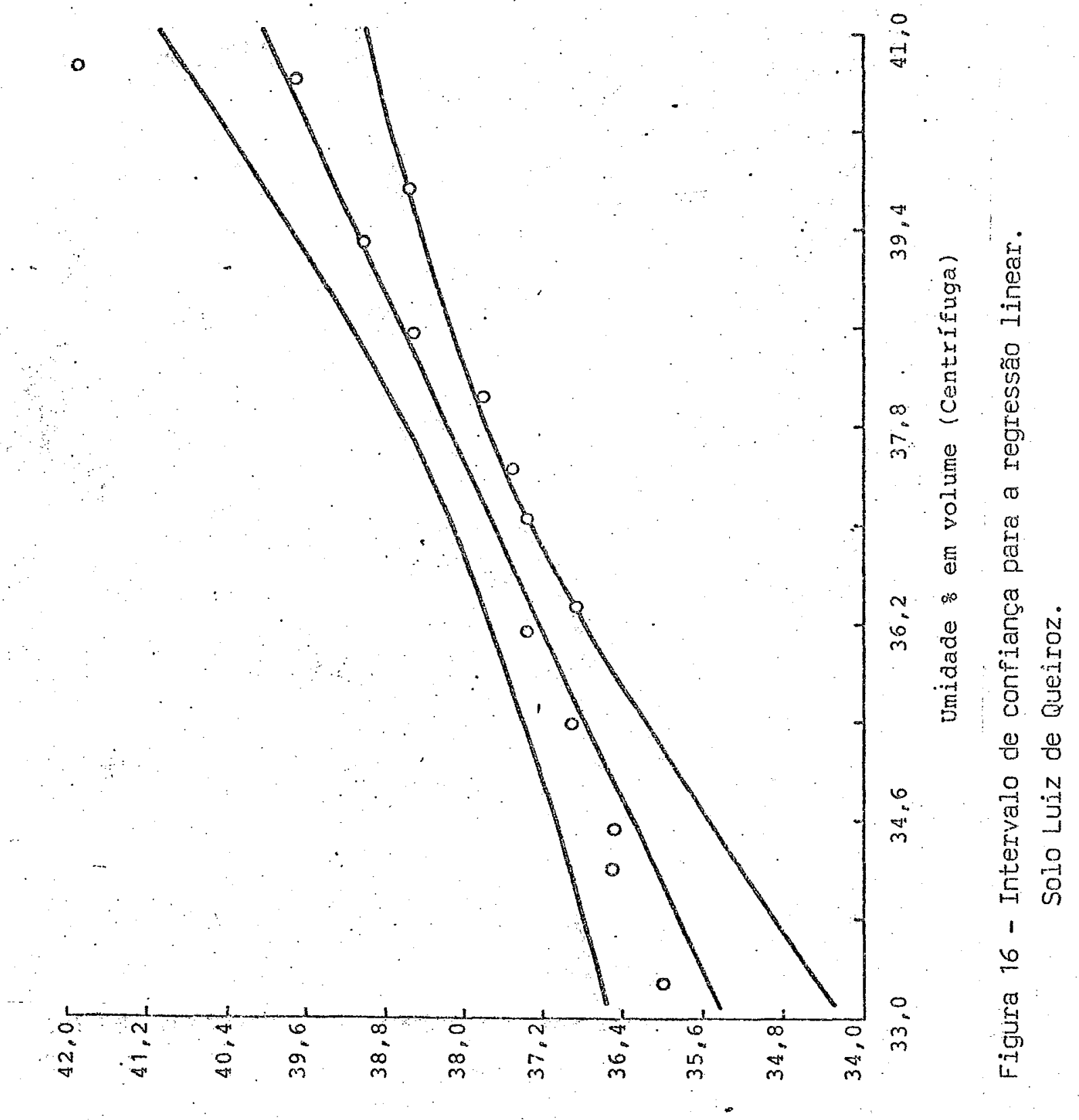

- (opssoxd op exeurgo) ournton urə o epeptun 


\section{CONCLUSÖES}

Nas condições em que foi conduzido este ex perimento e em face dos resultados obtidos, pode-se concluir que:

- o método de determinação da curva característica da água no solo pelo fatiamento de amostras centrifugadas, mostra uma correlação significativa com o méto do das câmaras de Pressão.

- A determinação àa curva característica da água no solo pelo método do fatiamento de amostras centrifugadas mostrou sua viabilidade em testes de rotina, desde que se disponha de equipamentos adequảos ao uso do mé todo. 


\section{RETERENCIAS BIBIIOGRAFTCAS}

ALEMI, M. H.; NIELSEN, D. R.; BIGGAR, J. W. Determining the hydraulic conductivity of soil cores by centrifuga tion. Soil Sci. Soc. Am, J., Madison, Wisconsin, 40: $212-8,1976$.

BRIGGS, L. J. \& MCLANE, J. W. The moisture equivalents of soils. Bureau of Soil. Washington, USDA. Bulletin, 45, 1907.

BRIGGS, L。J.\& MCIANE, J. W. Moisture equivalent determi nations and their application. Proc. Am. Soc. Agron., Washington, USDA., $2: 138-47,1910$.

COLMAN, E. A. A Laboratory Procedure for Determining the Field Capacity of Soils. Soil Sci. New Brunswick, N.J., $63: 277-283,1947$.

FREITAS JR., E. \& SILVA, E. M. Uso da Centrifuga para determinação da curva de retenção de água do solo, em uma única operação. Pesquisa Agropecuária Brasileira, Brasilia, 19 (11) : 1423 - 1.28, nov. 1984. 
GARDNER, R. Amethod of measuring the capillary tension of soil moisture over a wide moisture range. Soil Sci., New Brunswick, N. J., $43: 277-283,1937$.

GROHMANN, F. \& MEDINA, H. P. Características de Umidade dos Principais Solos do Estado de São Paulo. Bragantia Campinas. $21(18): 285-295,1962$.

HOFFMANN, R. \& VIEIRA, S. Análise de Regressão: Uma intro. dução à econometria. 2. ed. São Paulo, Hucitec, 1983. $379 \mathrm{p}$.

JAMISON, V.C. \& KROTH, E.M. AVOilable Moisture Storage Capacity in Relation to Textural Composition and Organic Matter Content of Several Missouri Soils. Soil Sci. Soc.

$\therefore \quad$ Am. Proc. Morgantawn, 22: 189-192, 1958.

LIBARDI, P. I. Dinâmica da água no sistema solo - PlantaAtmosfera. Piracicaba - SP, CENA/USP, 1984.232 p. (Mi meografado).

MACLEAN, A. H. \& YAGER, T.V. available water Capacities of Zambian Soils in Relation to Pressure plate Measurements and Particle Size Analysis. Soil Sci., New Bruns wick, N. J., 113 (1) : $23-29,1972$. 
PANINGBATAN JUNIOR, E. P. Determination of soil moisture characteristic and hidraulic conductivity using a centrifuge. Davis, 1980,198 p. $\left(P_{h}\right.$ D., University of Cali fórnia).

RANZANI, G.; FREIRE, O.; KINJO, T. Carta de Solos do Muni cípio de Piracicaba. Piracicaba - SṔ, Centro de Estudos de Solos - ESALQ/USP. 1966, 85 p.

REICHARDT, K. Processos de Transferência no Sistema so 10 - Planta - Atmosfera. 3. ed. Piracicaba - SP, CENAUSP - CNEN e Fundação Cargill. 1975, 286 p.

REICHARDT, K. A água na produção Agxícola. São Paulo, MCGrau - Hill. 1978, 115 p.

RICHARDS, L. A. \& FIREMAN, M. Pressure - Plate Apparatus for Measuring Sorption and transmission by Soils. Soil Sci. New Brunswick, N. J. 56 : $395-404,1943$.

RICHARDS, L. A. \& WEAVER, L. R. Fifteen -Atmosphere - Per centage as Related to the Permanent wilting Percentage. Soil Sci. New Brunswick, N. J., 56 : 331 - 339, 1943.

RUSSEL, M. B. \& RICHARDS, L. A. Tre determinatior of soir moisture energy relations by centrifugation. Soil sci. Am. Proc. Morgantown, west Virginia, $3: 65-9,1938$. 
SALTER, P. J. \& HAWORTH, F. The Availsble water Capacity of a Sondy Loam Soil. I. A Critical Comparison of Methods of determining the Moisture Content of soil at Field Capacity and the Permanent Wilting Point.J. Soil Sci. Oxford, Inglaterra, 12: $326-334,1961$.

SCARDUA, R. Porosidade Livre de Água de Dois Solos do Município de Piracicaba - SP. Piracicaba, 1972, 83 p. (Mestrado - Escola Superior de Agricultura "Luiz de Queiroz"/USP).

SCARDUA, R. Irrigação. Piracicaba." Centro Acadêmico "Luiz de Queiroz", 1984,198 p. (ivimeografado).

Soil Survey Staff. Sojl Taxonomy Agric. Handbook no 436. USDA-US Government Printing Office, Washington, DC. Agric. Handbook no 436, 1975.

THOMAS, M. D. \& HARRIS, K. The moisture equivalent of soils. Soil Sci. New Brunswick, N. J., 26 (6):411-24, 1925.

VEIHMEYER, F. J. \& HENDRICKSON, A. H. Methods of Measuring Field Capacity and Permanent wilting Percentage of Soils. Soil Sci,, New Brunswick, N. J., 68 : $75-94,1949$ 
VEIHMEYER, F. J.; ISRAELSEN, O. W.; CONRAD, L. P.The Mois ture equivalent as influenced by the amount of soil used in its determination. Univ. Califórnia, college of Agriculture, Agric. Exp. Station, Berkeley, 1924; Tech. paper, 16.

WINTER, E. J. A Agua, o solo e a Planta. trad.K.REICHARDT \& P. L. LIBARDI. Sào Paulo, EPU./EDUSP., 1976, 169 p. 
$\div 57$.

\section{APÊADICE}


.58 .

TABELA 2 - Valores médios do teor dé água do solo em função do tem po e da velocidade angular de centrifugação. Solo Luiz de Queiroz.

\begin{tabular}{|c|c|c|c|c|c|c|c|c|c|c|}
\hline \multirow{2}{*}{$\begin{array}{l}\text { Tempo } \\
\text { (min.) }\end{array}$} & \multicolumn{4}{|c|}{ Umidade } & \multirow{2}{*}{$\begin{array}{l}\text { Tempo } \\
(\min .)\end{array}$} & \multicolumn{4}{|c|}{ Umidade } & \multirow{2}{*}{ volume } \\
\hline & $\frac{\circ}{6}$ & en peso & $\frac{\circ}{0} \cdot \mathrm{em}$ & volume & & $\%$ & $\mathrm{em}$ & peso & $\frac{8}{8} \mathrm{em}$ & \\
\hline & & $v=720$. & $\mathrm{rpm}$ & & & 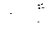 & $v=$ & $=1000$ & $\mathrm{rpm}$ & \\
\hline 30 & & 30,64 & & 41,97 & 30 & & & 30,34 & & 41.57 \\
\hline 60 & & 29,97 & & 41,06 & 60 & & & 29,86 & & 40,91 \\
\hline 120 & & 29,46 & & $40,3.6$ & $\therefore 120$ & & & $29,31$. & & 40,15 \\
\hline 180 & & 29,14 & & 39,92 & 180 & & & 28,96 & & 39.67 \\
\hline 240 & & 28,96 & & 39,68 & 240 & & & 28,73 & & 39,36 \\
\hline 300 & & 28,77 & & 39,41 & 300 & & & 28,55 & & 39,11 \\
\hline 330 & & 28,72 & & 39,35 & 330 & & & 28,45 & & 38,98 \\
\hline 340 & & 28,69 & & 39,31 & $340^{\circ}$ & . & & 27,88 & & 38,20 \\
\hline & & $v=1400$ & rpm & & & & $v=$ & $=1800$ & $\mathrm{rpm}$ & \\
\hline 30 & ' & 30,09 & & 41,22 & 30 & & & 28,97 & & 39,69 \\
\hline 60 & & $29,34$. & $\cdot$ & 40,19 & 60 & & & 28,20 & 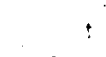 & 38.63 \\
\hline 120 & & 28,60 & : & 39.18 & 120 & & & 27,26 & & 37.35 \\
\hline 180 & & 28,24 & & 38,69 & 180 & & & 26,91 & & 36.87 \\
\hline 240 & & 27,92 & & 38,25 & 240 & & & 26,41 & & 36,18 \\
\hline 300 & & 27,69 & & 37,94 & 300 & & & 26,06 & & 35,70 \\
\hline 330 & 3 & 27,55 & & 37,74 & 330 & & & 25,85 & & 35.41 \\
\hline 340 & & 27,01 & & 37,00 & 340 & & & 25,77 & & 35,30 \\
\hline & & $v=2.30$ & $00 \mathrm{rpr}$ & & & & & & & . \\
\hline 30 & & 28,82 & & 39,48 & & & & & & \\
\hline 60 & & 28,01 & & 38,37 & & & . & & & \\
\hline 120 & & 27,20 & & 37.26 & & & & & & . \\
\hline 180 & & 26,75 & & 36,65 & & & & & & \\
\hline 240 & & 26,32 & & 36,06 & & & & & & \\
\hline 300 & & 25,99 & & 35,61 & & & $\therefore$ & & & \\
\hline 330 & & 25,77 & & 35,30 & . & & & & & \\
\hline 340 & & 25,69 & . & 35,20 & & & & & & \\
\hline
\end{tabular}


TABELA 10- Valores médios do teor de água do solo em função do tem po e da velocidade angular de centrifugação. Solo sertãozinho.

\begin{tabular}{|c|c|c|c|c|c|c|c|c|c|c|c|}
\hline Tempo & & & & Umida & ade & & Tempo & & Unialade & & . \\
\hline$(\min )$. & 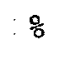 & em peso & & 웅 & em volt & ume & $(\min )$. & $\%$ & em peso & 8 & em volume \\
\hline$\therefore$ & & $\because$ & v & $=720$ & $\mathrm{rpm}$ & $\ldots$ & & & $v=1400$ & $\mathrm{rpm}$ & \\
\hline 15 & & 14.64 & & & 24.01 & & 15 & & 13,04 & & $21^{\circ}, 39$ \\
\hline 30 & & 14,24 & & & 23,35 & & 30 & & 12,18 & & 19,97 \\
\hline 60 & & 13,77 & & ? & 22,58 & & 60 & & 11,51 & & 18,87 \\
\hline 120 & & 13,18 & & & 21,62 & & 120 & & 10,76 & & 17,65 \\
\hline 180 & & 12,71 & & & 20,84 & ! & 180 & & 10,46 & & 17,15 \\
\hline 240 & & 12,46 & & & 20,43 & & 240 & & 10,23 & & 16,77 \\
\hline 300 & & 12,35 & & & 20,25 & & 300 & & $.10,04$ & & 16,47 \\
\hline 310 & & 12,10 & & & 19,84 & & 370 & & 10,00 & , & 16.40 \\
\hline & & & $\mathrm{v}$ & $=180$ & $00 \mathrm{rpm}$ & & & & $\mathrm{v} .=2$ & 300 & $\mathrm{rpm}$ \\
\hline 15 & & 12,20 & & & 20,00 & & 15 & & 11,60 & & 19,02 \\
\hline 30 & & 11,65 & & & 19,11 & & 30. & & 10,96 & & 17,97 \\
\hline 60 & & 11,10 & & & 18,20 & & 60 & & 10,38 & & 17.02 \\
\hline 120 & & 10,58 & & & 17.35 & & 120 & & 9,85 & & 16,15 \\
\hline 180 & & 10,22 & & $\cdot$ & 16,76 & & 180 & & $9 ; 51$ & & 15,59 \\
\hline 240 & & 9.91 & & & 16,25 & & 240 & & 9,19 & & 15,07 \\
\hline 300 & & 9,66 & & & 15,84 & & 300 & & 8,93 & & 14,65 \\
\hline 310 & & 9,46 & & & 15,51 & & 310 & & 8,74 & & 14,33 \\
\hline & & $\cdot$ & & & & $\cdot$ & & & & . & \\
\hline
\end{tabular}


Tabela 11 - Valores médios da tensão da água do solo, umidades : em pe so e en volume, determinada na cânara de pressão. Solo Iuiz de Queiroz $(20-40 \mathrm{~cm})$.

\begin{tabular}{|c|c|c|c|c|c|c|c|}
\hline $\begin{array}{l}\text { Tensão } \\
\text { (MPa) }\end{array}$ & & $\begin{array}{l}\text { Umidade } \\
\text { \& em peso: }\end{array}$ & & $\begin{array}{c}\mathrm{rg} \\
\left(\mathrm{g} / \mathrm{cm}^{3}\right)\end{array}$ & ' & $\begin{array}{l}\text { Unidade } \\
\text { em volume }\end{array}$ & $\begin{array}{l}\text { Unidade média } \\
\text { o em volune }\end{array}$ \\
\hline$\theta_{s}$ & & 37,46 & & 1,40 & & 52,44 & \\
\hline$\theta_{s}$. & & 36,98 & & 1,40 & & 51,77 & 52,10 \\
\hline 0,003 & & 31,55 & & 1,40 & $\ldots$ & 44,17 & \\
\hline 0,003 & & 30,92 & & 1,40 & & 43,28 & 43,72 \\
\hline 0,006 & & 30,10 & & 1,40 & & 42,14 & \\
\hline 0,006 & & 29,73 & & 1,40 & & 41,62 & 41,88 \\
\hline 0,01 & & 28,68 & & 1,39 & & 39,86 & $\cdot \cdot$ \\
\hline 0,01 & & 27,60 & & 1.42 & & 39,19 & $\because$ \\
\hline 0,01 & & 27,36 & & 1.47 & & 40,22 & 39,76 \\
\hline 0,03 & $\theta$ & 27,16 & & 1,39 & & $37,75^{\circ}$ & \\
\hline 0,03 & & 26,33 & & 1,42 & . & 37,39 & \\
\hline 0,03 & . & 26,11 & & 1,47 & & 48,38 & 37,84 \\
\hline 0,06 & & 27,10 & & 1,39 & & $3 \%, 67$ & \\
\hline 0,06 & & 25,87 & & 1,42 &. & 36,73 & \\
\hline 0,06 & & 25,73 & & 1,47 & & 37,82 & 37,40 \\
\hline $0,10^{\cdots}$ & & 26,64 & $\cdots$ & 1,39 & & 37,03 & \\
\hline 0,10 & & 25,58 & & 1,42 & & 36,32 & $\cdot$ \\
\hline 0,10 & $\therefore$ & 25,36 & & 1,47 & & 37,28 & 36,87 \\
\hline 0,30 & $\cdot$ & 23,89 & & 1,47 & & 35,11 & . \\
\hline 0,30 & & 23,89 & & 1,56 & & 37,26 & . \\
\hline 0,30 & & 23,81 & & 1,51 & & 35,95 & 36,11 \\
\hline 0,60 & & 22,76 & & $1, A 7$ & & 33,46 & \\
\hline 0,60 & & 22,59 & . & 1,56 & & 35,24 & \\
\hline 0,60 & & 22,54 & & $1,51^{\circ}$ & & 34,04 & 34,25 \\
\hline 1,50 & . & 21,89 & & 1,47 & & 32,18 & \\
\hline 1,50 & & $21 ; 23$ & & 1,56 & & 33,12 & . \\
\hline$\therefore>0$ & & 21,38 & & 1,51 & & 32,28 & 32,53 \\
\hline
\end{tabular}


Tabela 12 - Valores médios da tensão da água do solo, umidades o empe so e on volume, determinada na câmara de pressão. Solo Sertãozinho $(20-40 \mathrm{~cm})$.

\begin{tabular}{|c|c|c|c|c|}
\hline $\begin{array}{c}\text { Tensão } \\
\text { (MPa) }\end{array}$ & $\begin{array}{l}\text { Umidade } \\
\text { o em peso }\end{array}$ & $\frac{\gamma g}{\left(\mathrm{~g} / \mathrm{cm}^{3}\right)}$ & $\begin{array}{l}\text { Umidade } \\
\text { on volume }\end{array}$ & $\begin{array}{l}\text { Unidade nedia } \\
\text { \% en volume }\end{array}$ \\
\hline$\theta_{\mathbf{S}}$ & 23,61 & 1,59 & 37,54 & \\
\hline$\theta_{\dot{s}}$ & 22,89 & 1.58 & 36,17 & 36,85 \\
\hline 0,003 & 17,23 & 1,59 & 27,40 & \\
\hline 0,003 & 16,46 & 1,58 & 26,01 & 26,71 \\
\hline 0,006 & 15,14 & 1,59 & 24,07 & \\
\hline 0,006 & 14,38 & 1,58 & 22,72 & 23,39 \\
\hline 0,01 & 13,44 & 1,68 & 22,58 & \\
\hline 0,01 & 12,90 & 1,64 & 21,16 & \\
\hline 0,01 & 12,55 & 1,76 & 22,08 & 21,95 \\
\hline 0,03 & 10,21 & 1,68 & 17,15 & \\
\hline 0,03 & 9,94 & $\cdot 1,64$ & 16,30 & \\
\hline 0,03 & 9,62 & 1,76 & 16,93 & 16,79 \\
\hline 0,06 & 9,50 & 1,68 & 15,96 & \\
\hline 0,06 & 9,27 & 1,64 & 15,20 & . \\
\hline 0,06 & 8,99 & 1,76 & 15,82 & 15,66 \\
\hline 0,10 & 9,17 & 1,68 & 15,40 & \\
\hline 0,10 & 8,73 & 1,64 & 14,32 & \\
\hline 0,10 & 8,63 & 1.76 & 15,19 & 14,97 \\
\hline 0,30 . & 7,46 & 1,60 & 11,94 & \\
\hline 0,30 & 8,17 & 1,57 & 12,83 & \\
\hline 0,30 & 7,87 & 1,63 & 12,83 & 12,53 \\
\hline 0,60 & 6,91 & 1,60 & 11,06 & \\
\hline 0,60 & 7,49 & 1,57 & 11,76 & \\
\hline 0,60 & 7,42 & 1,63 & 12,09 & 11,64 \\
\hline 1,50 & 6,43 & 1,60 & 10,29 & \\
\hline 1,50 & 7,00 & 1,57 & 10,99 & .. \\
\hline 1,50 & $\therefore 5.90$ & 1,63 & $1+, 25$ & $\therefore$ in 84 \\
\hline
\end{tabular}


Tabela 13 - Valores da tensão da água do solo, umidade $\%$ em peso e $\%$ em volume, deterninada em centrífuga. Solo Iuiz de quei$\operatorname{roz}(20-40 \mathrm{~cm})$.

\begin{tabular}{|c|c|c|c|c|}
\hline $\begin{array}{l}\text { Tensão } \\
\text { (MPa) }\end{array}$ & $\begin{array}{l}\text { Unidade } \\
\text { \% em peso }\end{array}$ & $\frac{\mathrm{rg}}{\left(\mathrm{g} / \mathrm{cm}^{3}\right)}$ & $\begin{array}{l}\text { Umidade } \\
\text { \% en volume }\end{array}$ & $\begin{array}{l}\text { Unidade média } \\
\text { \% em volume }\end{array}$ \\
\hline & \multicolumn{4}{|c|}{$\mathrm{v}=720 \mathrm{rpm}$} \\
\hline 0,025 & 28,10 & 1,37 & 38,50 & \\
\hline 0,025 & 27,92 & 1,37 & $\because, 38,25$ & \\
\hline 0,025 & 28,45 & 1,37 & 39,98 & \\
\hline 0,025 & 25,57 & 1,37 & 37,77 & \\
\hline 0,025 & 28,60 & 1,37 & 39,18 & 38,54 \\
\hline 0,017 & 28,63 & 1,37 & 39,22 & \\
\hline 0,017 & 28,29 & 1,37 & 38,76 & \\
\hline 0,017 & 28,92 & 1,37 & 39,62 & \\
\hline 0,017 & 28,44 & 1.37 & 38,96 & . \\
\hline 0,017 & 29,05 & 1,37 & 39,80 & 39,27 \\
\hline 0,006 & 29,73 & 1,37 & 40,73 & \\
\hline 0,006 & 29,51 & 1,37 & 40,43 & \\
\hline 0,006 & 30,24 & 1,37 & 41,43 & \\
\hline 0,006 & 29,17 & 1.37 & 39,96 & \\
\hline \multirow[t]{2}{*}{0,006} & 30,04 & 1,37 & 41,15 & 40,74 \\
\hline & \multicolumn{3}{|r|}{$v=1000 \mathrm{rpm}$} & \\
\hline 0,048 & 27,13 & 1,37 & 37,17 & \\
\hline 0,048 & 27,09 & 1,37 & 37,11 & \\
\hline 0,048 & 28,05 & 1,37 & 38,43 & \\
\hline $0 ; 048$ & 27,17 & 1,37 & 37,22 & \\
\hline 0,048 & 27,25 & 1,37 & 37,33 & 37.45 \\
\hline 0,032 & 27,75 & 1,37 & 38,02 & \\
\hline 0,032 & 27,54 & 1,37 & 37,73 & \\
\hline 0,032 & 28,37 & 1,37 & 3,87 & \\
\hline 0,032 & 27,62 & 1,37 & 37,84 & \\
\hline 0,032 & 27,52 & 1,37 & 37,70 & 30,03 \\
\hline
\end{tabular}


Tabela 13 - cont.

\begin{tabular}{|c|c|c|c|c|c|}
\hline $\begin{array}{l}\text { Tensão } \\
\text { (MPa) }\end{array}$ & $\begin{array}{l}\text { Umidade } \\
\text { \% em peso }\end{array}$ & $\begin{array}{c}\mathrm{yg} \\
\left(\mathrm{g} / \mathrm{cm}^{3}\right)\end{array}$ & & $\begin{array}{l}\text { Unidade } \\
\text { em volume }\end{array}$ & $\begin{array}{l}\text { Unidade média } \\
\text { o en volume }\end{array}$ \\
\hline 0,012 & 29,53 & 1,37 & & 40,46 & \\
\hline 0,012 & 29,64 & 1,37 & & 40,61 & \\
\hline 0,012 & 29,80 & 1,37 & & 40,83 & \\
\hline 0,012 & 29,71 & 1,37 & & 40,70 & \\
\hline \multirow[t]{2}{*}{0,012} & 29,57 & 1,37 & - & 40,51 & 40,62 \\
\hline & & & $r=1400$ & $\mathrm{rpm}$ & \\
\hline 0,093 & 26,36 & 1,37 & & 36,11 & \\
\hline 0,093 & 26,19 & 1,37 & & 35,88 & \\
\hline 0,093 & 25,06 & 1,37 & & 34,33 & \\
\hline 0,093 & 25,68 & 1,37 & & 35,18 & \\
\hline 0,093 & 25,83 & 1.37 & & 35,39 & 35,38 \\
\hline 0,062 & 27,75 & 1.37 & & 38,02 & \\
\hline 0,062 & 26,50 & 1,37 & & 36,31 & \\
\hline 0,062 & 27,33 & 1.37 & & 37,44 & \\
\hline 0,062 & 26,68 & 1,37 & & 36,55 & \\
\hline 0,062 & 26,89 & 1,37 & & 36,84 & 37,03 \\
\hline 0,023 & 29,19 & 1,37 & & 39,99 & \\
\hline 0,023 & 28,42 & 1,37 & & 38,94 & , \\
\hline 0,023 & $29 ; 39$ & 1,37 & . & 40,26 & \\
\hline 0,023 & 28,70 & 1,37 & & 39,32 & \\
\hline \multirow[t]{2}{*}{$0,023}$. & 29,28 & 1,37 & & 40,11 & 39,72 \\
\hline & & & $V=1800$ & 0 rom & \\
\hline 0,752 & 25,07 & 1,37 & & 34,35 & \\
\hline 0,152 & 25,31 & 1,37 & & 34,67 & \\
\hline 0,152 & 24,66 & 1,37 & & 33,78 & \\
\hline 0,152 & 24,96 & 1,37 & & 34,20 & \\
\hline 0,152 & 24,85 & 1,37 & & 34,04 & 34,21 \\
\hline 0,103 & 26,84 & 1,37 & & 36,77 & \\
\hline 0,103 & 27,19 & 7,37 & & 37,25 & \\
\hline
\end{tabular}


Tab. $13^{-}$- cont.

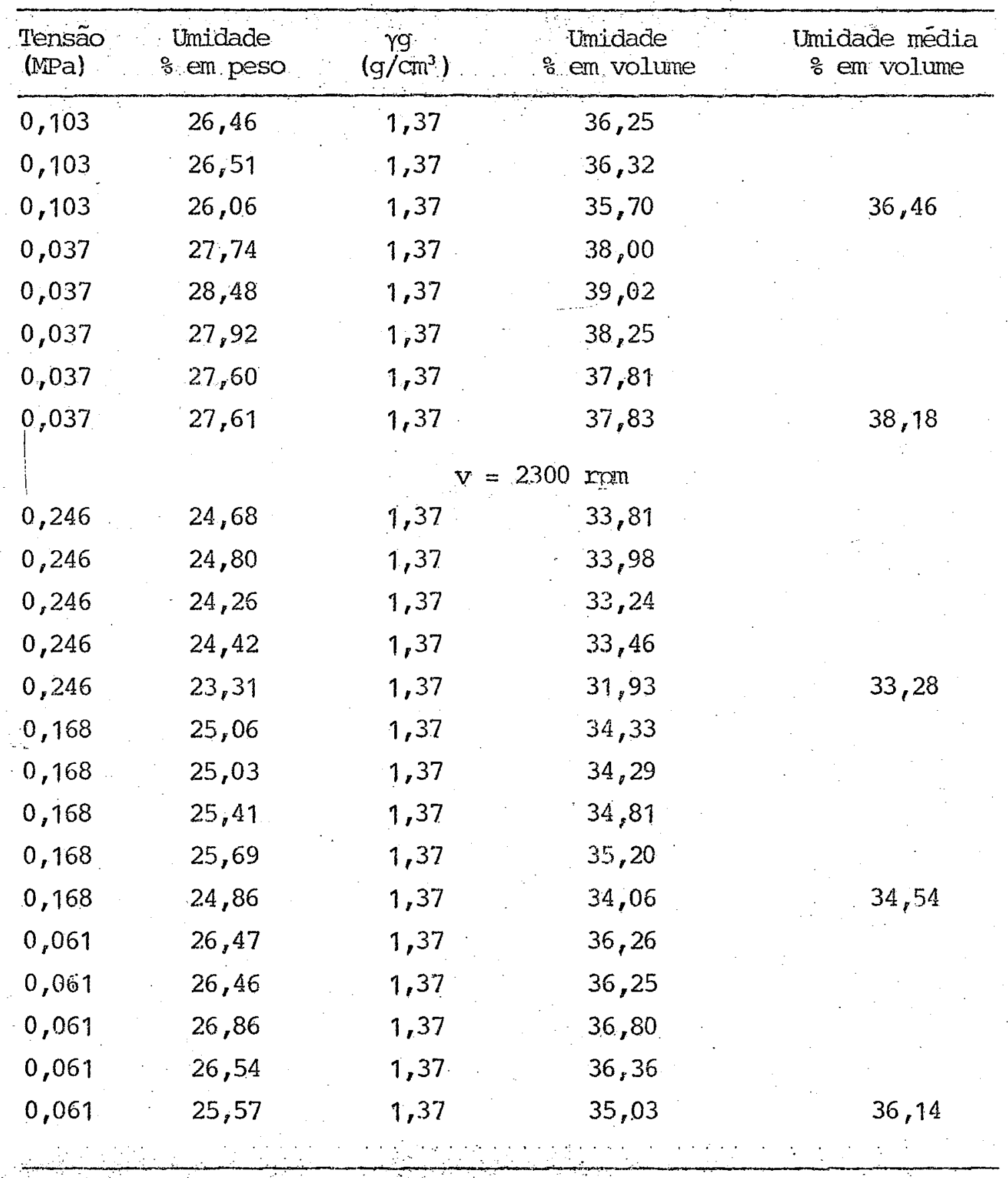


Tabela 14 - Tabela da tensão da áqua do solo, umidades : em peso e : em volume, determinada na centrifuga. Solo Sertãozinho (20 - 40 $\mathrm{cm})$.

\begin{tabular}{|c|c|c|c|c|c|c|c|c|}
\hline $\begin{array}{l}\text { Tensão } \\
\text { MPa }\end{array}$ & & $\begin{array}{l}\text { nidade } \\
\text { em peso }\end{array}$ & $\begin{array}{l}\mathrm{rg} \\
\mathrm{g} / \mathrm{cm}^{3}\end{array}$ & & $\frac{8}{8}$ & $\begin{array}{l}\text { Umidade } \\
\text { en volume }\end{array}$ & $\begin{array}{l}\text { Umi } \\
\text { : }\end{array}$ & $\begin{array}{l}\text { idade média } \\
\text { em volume }\end{array}$ \\
\hline 0.025 & & 10,45 & $1,64=$ & 720 & & $\mathrm{pm}_{17,13}$ & & $\therefore$ \\
\hline 0,025 & $\because$ & 10,56 & 1,64 & & & 17,32 & & \\
\hline 0,025 & & 10,21 & 1,64 & $\ldots$ & & 16,74 & $\cdot$ & \\
\hline 0.025 & & 10,25 & 1,64 & & & 16,81 & & \\
\hline 0,025 & 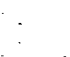 & 11,09 & 1,64 & : & $:$ & 18,19 & $\ddots$ & 17,24 \\
\hline 0,017 & & 11,63 & 1,64 & & & 19.08 & & \\
\hline 0,017 & & 11,26 & 1,64 & & & 18,46 & & \\
\hline 0,017 & & 10,75 & $-1,64$ & & & 17,63 & & \\
\hline 0.017 & & 10,78 & 1.64 & & & 17,68 & & $\because$ \\
\hline 0.017 & & 12.51 & 1,64 & & & 20,52 & & 18,67 \\
\hline 0,006 & $\cdot$ & 13,32 & 1,64 & & & 21,84 & & $\therefore$ \\
\hline 0,006 & & 12,35 & 1,64 & & & 20,25 & & \\
\hline 0,006 & & 12,11 & $i, 64$ & & & 19.86 & & \\
\hline 0,006 & & 11.76 & 1,64 & & & 19,29 & & $\therefore$ \\
\hline 0,006 & & 14.79 & $\begin{array}{c}1,64 \\
v=\end{array}$ & 140 & & $\begin{array}{l}24,26 \\
\text { rpm }\end{array}$ & & 21,10 \\
\hline 0.093 & $\Rightarrow$ & 8,48 & 1,64 & & & 13,90 & & \\
\hline 0.093 & . & 8.11 & 1,64 & & & 13,30 & $\because$ & \\
\hline 0.093 & & 8,36 & 1,64 & & & 13,71 & . & \\
\hline 0,093 & & 7,68 & 1,64 & & & 12,60 & & \\
\hline 0,093 & & 8,25 & 1,64 & & & 13,53 & & 13,41 \\
\hline 0,062 & & 9,13 & 1,64 & & & 14,97 & & \\
\hline 0,052 & & 9,17 & 1,64 & & & 15,04 & & \\
\hline $0,0,62$ & & 9,19 & 1,64 & & & 15,07 & & \\
\hline 0,062 & & 9,01 & 1,64 & & & 14.78 & & . \\
\hline 0,052 & & $9,03$. & 1,64 & & & 14.81 & $\therefore$ & $\ldots 14,93$ \\
\hline 0,023 & & 10,35 & 1,64 & & & 16.97 & & \\
\hline $0,023$. & & 10,11 & 1,64 & & & 16,58 & & \\
\hline 0,023 & & 10,51 & 1.64 & & & $17: 24$ & & . \\
\hline 0,023 & & 10,02 & 1,64 & 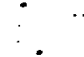 & & 16,43 & & \\
\hline 0,023 & & 10,66 & 1.64 & & & 17,49 & . & 16.94 \\
\hline
\end{tabular}


Tabela 14 - cont.

\begin{tabular}{|c|c|c|c|c|c|c|c|c|}
\hline $\begin{array}{c}\text { Tensão } \\
\text { MPa }\end{array}$ & $\therefore \quad$ & $\begin{array}{l}\text { Umidade } \\
\text { : em peso }\end{array}$ & & $\frac{\mathrm{rg}}{\mathrm{g} / \mathrm{cm}^{3}}$ & $\therefore \quad$ 8 & $\begin{array}{l}\text { Umidade: } \\
\text { em volume }\end{array}$ & \multicolumn{2}{|c|}{$\begin{array}{l}\text { Umidade média } \\
\text { \& em volume }\end{array}$} \\
\hline 0.152 & & 7,39 & & $\begin{array}{c}V_{1,64} \\
1800\end{array}$ & $\mathrm{rpm}$ & 12,12 & & \\
\hline 0.152 & & 8,08 & & 1,64 & & 13,25 & & $\therefore$ \\
\hline 0,152 & & 7,91 & & 1,64 & & 12,97 & & \\
\hline 0,152 & & 8,39 & & 1,64 & & 13,76 & & \\
\hline 0,152 & & 8,20 & & 1,64 & & 13,45 & & 13,11 \\
\hline 0,103 & & 8,64 & & 1,64 & & 14.17 & $\cdot$ & \\
\hline 0,103 & & 8,91 & & 1,63 & & 14.61 & . & \\
\hline 0.103 & & 8,66 & . & 1,64 & & 14,21 & & : \\
\hline 0,103 & $\cdot$ & 9,03 & & 1.64 & & 14,81 & & \\
\hline 0,103 & & 8,60 & & 1,64 & & $14,1 ?$ & . & 14,38 \\
\hline 0,037 & & 9,69 & & 1,64 & & $15,89^{\circ}$ & & 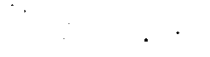 \\
\hline 0,037 & & 10,09 & & 1,64 & & 16,55 & . & \\
\hline 0,037 & & 9,51 & & 1,64 & & 15,60 & & \\
\hline 0,037 & . & 10,03 & & 1,64 & & 16,45 & & $t$ \\
\hline 0,037 & & 9,97 & & $\begin{array}{l}1.64 \\
v=230\end{array}$ & $00 \mathrm{rpm}$ & 16,35 & & 16.17 \\
\hline 0,246 & & 8,46 & & 1,64 & & 13,87 & & : \\
\hline 0,246 & & 8,18 & & 1,64 & & 13,41 & & $\therefore$ \\
\hline 0,246 & & 7,44 & & 1.64 & & 12,21 & & \\
\hline 0,246 & & 7,92 & & 1,64 & & 12,99 & & 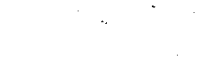 \\
\hline 0,246 & & 7,67 & & 1,64 & & 12,58 & 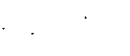 & 13,01 \\
\hline 0,168 & & -9.20 & & 1,64 & & 15,09 & · & \\
\hline 0,168 & & 8,59 & & 1,64 & & 14,09 & . & 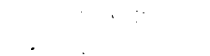 \\
\hline 0,168 & & 8,22 & & 1,64 & & 13.48 & & \\
\hline 0,168 & $\because$ & 8,29 & & 1.64 & & 13,59 & & \\
\hline 0,168 & & 8,20 & & 1,64 & & 13,45 & & 13,94 \\
\hline 0.061 & & 9,81 & & 1,64 & & 16,09 & & \\
\hline 0,061 & & 9,48 & & 1,64 & & 15.54 & & \\
\hline 0,061 & & 9,07 & & 1,64 & & 14,87 & & 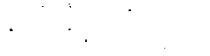 \\
\hline 0,061 & & 8,70 & & $i, 64$ & & 14,27 & & 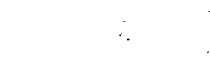 \\
\hline 0,061 & & 8,86 & 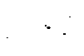 & 1,64 & & 14,53 & & $15,0=$ \\
\hline
\end{tabular}

